\title{
The Business Process Design Space for exploring process redesign alternatives
}

\author{
Steven Gross
}

Institute for Data, Process and Knowledge Management, Vienna University of Economics and Business, Vienna, Austria

Katharina Stelzl

FIM Research Center Finance \& Information Management, University of Bayreuth, Bayreuth, Germany

Thomas Grisold

Institute for Information Systems, University of Liechtenstein, Vaduz, Liechtenstein Jan Mendling

Institute for Data, Process and Knowledge Management, Vienna University of Economics and Business, Vienna, Austria

\section{Maximilian Röglinger}

FIM Research Center Finance \& Information Management, Project Group Business \& Information Systems Engineering of the Fraunhofer FIT, University of Bayreuth, Bayreuth, Germany, and

\section{Jan vom Brocke}

Institute for Information Systems, University of Liechtenstein, Vaduz, Liechtenstein

\begin{abstract}
Purpose - Process redesign refers to the intentional change of business processes. While process redesign methods provide structure to redesign projects, they provide limited support during the actual creation of to-be processes. More specifically, existing approaches hardly develop an ontological perspective on what can be changed from a process design point of view, and they provide limited procedural guidance on how to derive possible process design alternatives. This paper aims to provide structured guidance during the to-be process creation.

Design/methodology/approach - Using design space exploration as a theoretical lens, the authors develop a conceptual model of the design space for business processes, which facilitates the systematic exploration of design alternatives along different dimensions. The authors utilized an established method for taxonomy development for constructing the conceptual model. First, the authors derived design dimensions for business processes and underlying characteristics through a literature review. Second, the authors conducted semistructured interviews with professional process experts. Third, the authors evaluated their artifact through three real-world applications.

Findings - The authors identified 19 business process design dimensions that are grouped into different layers and specified by underlying characteristics. Guiding questions and illustrative real-world examples help
\end{abstract}

(C) Steven Gross, Katharina Stelzl, Thomas Grisold, Jan Mendling, Maximilian Röglinger and Jan vom Brocke. Published by Emerald Publishing Limited. This article is published under the Creative Commons Attribution (CC BY 4.0) licence. Anyone may reproduce, distribute, translate and create derivative works of this article (for both commercial and non-commercial purposes), subject to full attribution to the original publication and authors. The full terms of this licence may be seen at http:// creativecommons.org/licences/by/4.0/legalcode

This research has been funded by ERASMUS+ (EU Funding 2018-1-LI01-KA203-000114, "Reference Module Design for Explorative Business Process Management").

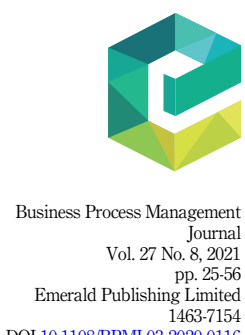

Received 23 March 2020

Revised 20 August 2020

1 October 2020

Accepted 27 October 2020 
BPMJ 27,8

to deploy these design dimensions in practice. Taken together, the design dimensions form the "Business Process Design Space” (BPD-Space).

Research limitations/implications - Practitioners can use the BPD-Space to explore, question and rethink business processes in various respects.

Originality/value - The BPD-Space complements existing approaches by explicating process design dimensions. It abstracts from specific process flows and representations of processes and supports an unconstrained exploration of various alternative process designs.

Keywords Business process redesign, Process improvement, Process innovation, Design space exploration Paper type Research paper

\section{Introduction}

Adopting and transforming business processes (processes hereafter) is essential for organizations to cope with increasing competition and customer expectations (Harmon and Garcia, 2020; Huang et al., 2015), especially in a hyper-connected world (Beverungen et al., 2020). Process redesign refers to the analysis and design of processes within and between organizations (Davenport and Short, 1990) and aims at changing the way work is accomplished and value is delivered (Dumas et al., 2018). Process redesign is a central part of business process management (BPM) and is supported by several BPM capabilities in the digital age (Kerpedzhiev et al., 2020). Because of their strategic importance, process redesign projects may entail large human and technical investments but may also yield substantial returns (Huang et al., 2015).

A plethora of methods and techniques support the systematic redesign of processes (Brocke et al., 2020; Dumas et al., 2018; Gross et al., 2019). While these approaches structure redesign projects into a logical sequence of steps, they are restricted regarding their ontological and procedural guidance during the actual act of creating new to-be process designs. In terms of ontological guidance, many approaches provide no or limited support on what can be changed from a process design perspective. In terms of procedural guidance, methods define phases and activities for redesign projects but lack structured support for designing new processes - which often happens in a "black box" (Denner et al., 2018; Zellner, 2011, p. 217). Hence, the creation of to-be process designs largely remains the result of a creative process (Figl and Recker, 2016; Sharp and Mcdermoot, 2009, p. 323; Vanwersch et al., 2015). Divergent thinking and creative techniques have been proposed for challenging thought boundaries in process redesign (Grisold et al., 2019; Kirchmer, 2017), but they suffer from limited reliability and consistency (Lee, 2014) as well as from potential biases (Afflerbach et al., 2017). The missing guidance during the creation of to-be process designs hinders organizations to realize the full potential of process redesign projects. Consequently, organizations may not completely reach their actual value creation potential.

Against this backdrop, this paper addresses the research problem of fostering the exploration of alternative process designs through explicit ontological guidance. More specifically, we aim to answer the research question: What are relevant dimensions for exploring process redesign alternatives? To this end, we built on the design space concept (Dove et al., 2016; Maclean et al., 1991) and developed a "Business Process Design Space" (BPD-Space) using the taxonomy development method by Nickerson et al. (2013). The design space concept has received attention in recent process redesign literature (Rosemann, 2020; Wurm et al., 2019), but the idea has not yet been operationally defined. As we demonstrate in our evaluation, discussing the dimensions of the BPD-Space helps to break out of constraining thought boundaries. In summary, our contribution is a conceptual model of process design dimensions together with exemplary characteristics, guiding questions and examples, which collectively build the BPD-Space. Empirically generated application guidelines support to use the BPDSpace in redesign projects. We thereby provide comprehensive ontological and initial procedural support during the to-be process creation.

This paper proceeds as follows. In section 2, we review existing process redesign approaches and introduce the design space concept. In section 3, we outline our research 
method. In section 4, we introduce the BPD-Space, while section 5 presents its evaluation. In section 6, we lay out implications, application guidelines, limitations and directions for future research. Section 7 concludes the paper.

\section{Background}

\subsection{Existing process redesign approaches}

Process redesign refers to the intentional change of processes within and beyond organizational boundaries (Davenport and Short, 1990) and is an essential part of the BPM discipline (Dumas et al., 2018). Process redesign methods have been highlighted as a critical success factor (Rosemann and vom Brocke, 2015) and provide guidance in a step-wise manner (Mendling et al., 2020). Techniques assist in performing one or more method's activities (Brinkkemper, 1996) and are thus narrowly focused on a specific outcome. For instance, a technique might focus on the diagnose or redesign of a process, two consecutive phases in a process redesign project (Gross et al., 2019; Kettinger et al., 1997).

A wide range of process redesign methods and techniques exists (Brocke et al., 2020; Dumas et al., 2018; Gross et al., 2019). These redesign approaches can be characterized based on their nature (which can be analytical or creative), perspective (inward-looking or outwardlooking) and ambition (transactional or transformational) (Dumas et al., 2018). Based on methods and techniques discussed in reviews and articles on process redesign and service design (Bettencourt et al., 2013; Bitner et al., 2008; Dumas et al., 2018, p. 306 ff; Frank et al., 2020; Lee et al., 2008; Malone et al., 1999; Rosemann, 2020; Vanwersch et al., 2015), we further distinguish seven underlying rationales of existing redesign approaches (Table 1). The identified redesign rationales are (1) problem-based, (2) imitation-based, (3) pattern-based, (4) interaction-based, (5) outcome-based, (6) customer-based and (7) alternative-based. While they are non-exclusive, we observe that one rationale typically predominates.

We describe the different rationales in more detail below.

(1) Most prominently, problem-based process redesign approaches like lean management (Bortolotti and Romano, 2012) and six sigma (Kwak and Anbari, 2006) aim at continuously tweaking existing processes through the identification and elimination of process problems. These approaches are problem-based, in the sense that they aim at improving issues or bottlenecks (Van den Bergh et al., 2014; Grisold et al., 2019) and thus mainly investigate the problem space of processes. As an example, lean management classifies different types of waste to be avoided, while non-value-adding process activities should be eliminated.

(2) Imitation-based approaches like benchmarking (König et al., 2019) and positive deviance (Setiawan and Sadiq, 2013) search for superior process designs with the aim to imitate (part of) the process' design, which causes this effective behavior.

(3) Pattern-based approaches build on this imitation rationale by abstracting from various real-world examples to sketch out useful and proven solutions. Representatives of this group are best practices of process redesign (Reijers and Liman Mansar, 2005), explorative process design patterns (Rosemann, 2020), customer-centric design patterns (Frank et al., 2020) and the Rethink of Process (RePro) principles (Vanwersch et al., 2015). Business process reengineering (BPR) also belongs to this set of approaches. Besides its radical ambition and clean-slate approach, it builds on several principles (i.e. higher-order patterns) that have been found to improve business process work (e.g. by involving as few people as possible in the performance of a business process) (Hammer and Champy, 1993). Anti-patterns follow a similar rationale by abstracting from common mistakes (Koschmider et al., 2019). 


\section{BPMJ \\ 27,8}

28

\begin{tabular}{|c|c|c|c|}
\hline & 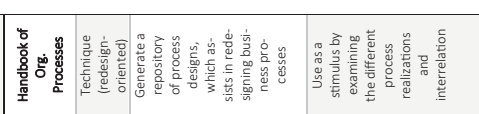 & - mDnuly & OMn \\
\hline & 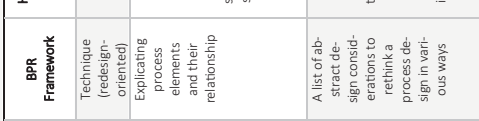 & - MII & - Mm: \\
\hline & nulyum diln & ollmin & - InI \\
\hline & 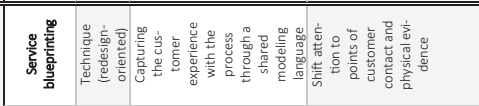 & - Mmp & - m \\
\hline & 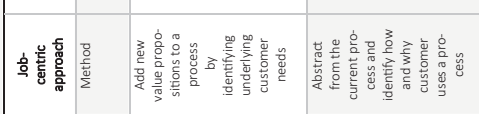 & $0 \mathrm{~min}$ & o \\
\hline & 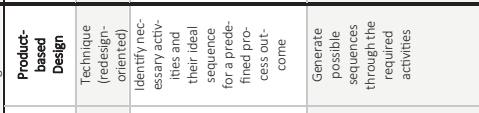 & - IIIII & - Mnus \\
\hline & 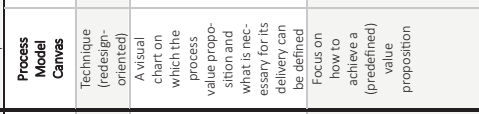 & - InIn & - IIn \\
\hline & 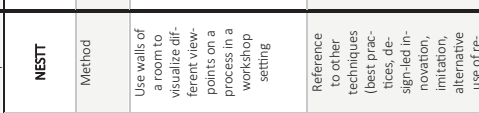 & OMWm & olmin: \\
\hline & 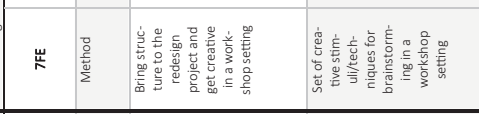 & olvin & OMn \\
\hline & 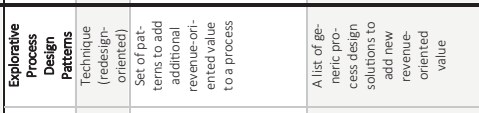 & 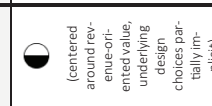 & OMUmi \\
\hline & 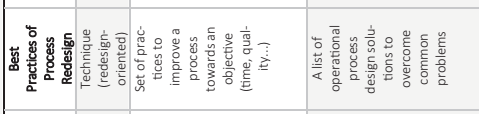 & - MWEn & - MnIm \\
\hline & 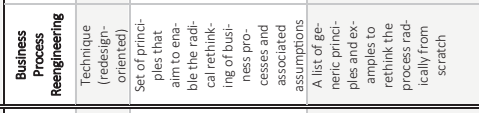 & -1 & - $\| m n^{2}$ \\
\hline & 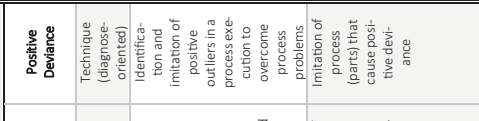 & O MWE & - In \\
\hline & 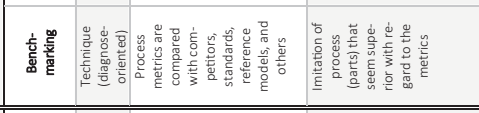 & o ImLi & - Ml \\
\hline & 11 Mumbun Ins & OIIn & ollin \\
\hline & 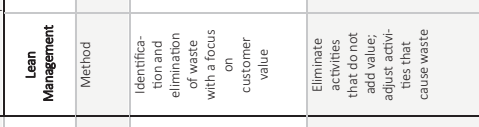 & OMn & ०III \\
\hline n & $1 \| \frac{1}{11}$ & In & mII \\
\hline
\end{tabular}

Table 1.

Comparison of existing process redesign approaches, their underlying rationales and ontological and procedural redesign guidance 
(4) Interaction-based approaches like 7FE (Jeston and Nelis, 2008) and NESTT (Rosemann, 2017) enable process redesign by providing guidance on the interaction of process redesign participants and artifacts, e.g. by using the walls of a room to visualize, organize and discover different viewpoints on a process in the NESTT method. They may also specify roles for the redesign project, as does 7FE with the specification of a redesign facilitator (Jeston and Nelis, 2008).

(5) Outcome-based approaches like product-based design (Reijers et al., 2003) or the process model canvas (Koutsopoulos and Bider, 2018) follow an end-to-start logic. They predefine a desired process outcome and reverse-engineer an ideal process design for reaching this outcome.

(6) Customer-based approaches like service blueprinting (Bitner et al., 2008) and the jobcentric approach (Bettencourt et al., 2013) identify and analyze a process from the customer point of view. Compared to outcome-based approaches, customer-based approaches are more outward-looking, with the customer as the main point of reference.

(7) Finally, alternative-based approaches like process grammar (Lee et al., 2008), the handbook of organizational processes (Malone et al., 1999) or the BPR framework (Reijers and Liman Mansar, 2005) aim to explore a wide range of possible process design alternatives without investigating prior process problems. Thus, they are opportunity-driven (Grisold et al., 2019). They build on the underlying assumption that some alternatives within this range outperform the status quo.

As indicated, a redesign method or technique can build on more than one of the previously described rationales. For instance, lean management is problem-based as well as customercentric. Its intention to avoid non-value-adding activities from the customer point of view can yet be regarded as problem-based, which thus manifests the method's primary rationale.

\subsection{Ontological and procedural aspects of process redesign}

Existing process redesign approaches provide limited support during the actual creation of to-be process designs (Sharp and Mcdermoot, 2009, p. 323; Vanwersch et al., 2015; Zellner, 2011, p. 217), as we will further explore in this section. The creation of to-be process designs is a critical part of redesign endeavors and refers to the creation of one or more design alternatives. While the underlying rationales of existing redesign approaches offer different frames of reference for the redesign task, most redesign approaches do not explicate the exploration and creation of to-be processes (Sharp and Mcdermoot, 2009, p. 323). This often "happens in a black box" (Zellner, 2011, p. 217), i.e. it is left to the user to creatively generate tobe processes, before their evaluation and selection. The challenge of generating to-be processes can be viewed through two distinct yet related perspectives.

First, methods and techniques follow the underlying assumption that process redesign alternatives are available (i.e. more than one potential to-be process), but hardly develop an ontological perspective on what can be changed from a design point of view. For instance, lean management follows the idea to eliminate different types of waste (Bortolotti and Romano, 2012), but there are numerous design choices on what to change to avoid waste. The waste of motion, for example, can be countered by the integration (or exclusion) of resources, decisions, activities and events, or by adjusting the sequence or message flow, to name but a few alternatives. However, the method itself does not explicate these design choices nor the resulting alternatives. Rather, it depends on the user to find appropriate leverage points in response to an identified waste. Other approaches focus on specific design aspects of processes while neglecting others. Product-based design (Reijers et al., 2003), for instance, 
BPMJ 27,8

mainly focuses on the sequence flow, while the explorative process design patterns (Rosemann, 2020) center around the revenue generation through a process. Thus, what is missing is a holistic understanding of redesign choices, considering and placing equal emphasis on all design choices of a business process.

Second, many redesign approaches provide limited procedural guidance on how to derive possible process design alternatives. Sticking to the example of lean management, the approach provides a general structure for redesign projects but does not define a procedure to create new process designs in which a certain waste is eliminated. Some approaches provide more explicit procedural guidance but are limited in their scope. A product-based design, for instance, provides structured guidance for the identification of possible sequence flows, but no procedure for other aspects of a process. Other approaches explicitly depend on creativity for the identification of design alternatives, e.g. 7FE (Jeston and Nelis, 2008) or service blueprinting (Bitner et al., 2008). Offering an ontological perspective provides at least some procedural guidance, as iterating through explicated design elements can be used for the creation of design alternatives. However, procedural guidance does not necessarily come with an ontological perspective.

There are a few examples of more explicit guidance (Vanwersch et al., 2016). Within pattern-based approaches, a pattern offers a specific recommendation for action, e.g. Contact reduction or Task elimination (Reijers and Liman Mansar, 2005). However, pattern-based approaches often focus on specific aspects of a process, e.g. revenue-oriented value for the explorative process design patterns (Rosemann, 2020), and thereby offer only a limited ontological perspective. Their underlying design choices are also partially implicit and not explicit (Lee, 2014). For instance, the pattern contact reduction (Reijers and Liman Mansar, 2005) can be used to question the necessity of existing points of contacts, but not to explore other possible forms of interaction with the customer.

Alternative-based approaches might have the potential to respond to the previously stated ontological and procedural challenges of existing process redesign approaches, as they aim for a wide exploration of process design alternatives. Explicit procedural guidance on the derivation of redesign alternatives is provided by the process grammar technique, which describes valid structural possibilities (i.e. combinations of process elements) in a given domain (Lee et al., 2008). A predefined grammar can thereby be used to algorithmically generate possible alternatives under specified constraints (Lee et al., 2008). However, this approach does not explicate the design elements of business processes and thus leaves it to its user to specify ontological design choices. More ontological guidance is offered by the BPR framework. This framework explicates six linked elements that should be considered in BPR projects (Reijers and Liman Mansar, 2005). These elements are, for instance, the customers of the process and the products or services generated for the customer. While these elements offer a high-level ontological perspective, they may be too abstract for the creation of to-be process designs and do not explicate possible design manifestations. Table 1 gives an overview of prominent redesign approaches for each redesign rationale and summarizes their core idea, implications for redesign, together with an assessment of their ontological and procedural guidance.

\subsection{Toward a design space and design dimensions}

The ontological challenge of process redesign can be approached using the design space concept. A design space is a "space of possibilities" (Maclean et al., 1991, p. 203) in which design ideas are created and considered (van Amstel et al., 2016). It is a conceptual model that contains design alternatives (Dove et al., 2016). To provide structure, an artifact and potential design alternatives are thereby placed along design dimensions (Maclean et al., 1991). Design dimensions comprise characteristics (i.e. design choices) by which possible artifact 
manifestations differ. Thereby, they provide an ontological design perspective. A desk, for instance, has height, width and length as spatial design dimensions with any length specifications as characteristics. Other design dimensions are color (with characteristics such as white or blue), material (e.g. wood, glass) or shape of the tabletop (e.g. rectangular, round). Thus, design dimensions offer an angle to dynamically remove, add or create new artifact manifestations (Crilly and Cardoso, 2017).

The explication of and reflection on a design space increases the awareness of constraints that come with particular design choices and how these can be challenged (Dove et al., 2016). It can also make a wider range of design aspects explicit, which were previously disregarded (Dove et al., 2016). This is particularly useful for less experienced designers (Dove et al., 2016). A representation of a design space thereby does not (and cannot) capture all design aspects, but provides useful guidance during the design process (Crilly and Cardoso, 2017). As such, the design space concept has been applied in various contexts, e.g. for the design of microservice decision logics (Haselbock et al., 2018), for the design of visualization tasks (Schulz et al., 2013), for the design of deep learning approaches for entity matching (Mudgal et al., 2018) and for structuring process architectures (Lapouchnian et al., 2015).

The procedural aspect of generating and evaluating design alternatives is called exploration (Navinchandra, 1991, p. 67). Investigating the design space supports the design process by defining design choices, which in turn enable the creation of new artifacts (Maclean et al., 1991; Mose Biskjaer et al., 2017). For this purpose, Maclean et al. (1991) introduced Design Space Analysis, which assists the exploration of the design space through specific questions, options and criteria. Questions are meant to introduce design dimensions and to structure and explore possible alternatives in the form of options (Maclean et al., 1991). Design options (also referred to as characteristics) offer possible alternative answers to questions to choose from (Maclean et al., 1991). Criteria support the evaluation of alternatives (Maclean et al., 1991), e.g. according to time, flexibility, quality or costs (Reijers and Liman Mansar, 2005). A design space schema is a graphical representation of a design space that displays design dimensions and possible characteristics (Crilly and Cardoso, 2017).

While the previously mentioned approaches like Design Space Analysis (Maclean et al., 1991) and the process grammar (Lee et al., 2008) build on the design space concept for determining alternative process designs, they do not explicate the design dimensions of processes. Thus, the identification and selection of design dimensions in process redesign projects leave the involved project members to their own devices. This is especially challenging for persons with limited redesign experience (Dove et al., 2016). Other approaches claim to have broadened the design space, without having defined its dimensions (Rosemann, 2020; Wurm et al., 2019). The BPR framework (Reijers and Liman Mansar, 2005) offers highlevel design dimensions, but can be too abstract for covering the BPD-Space adequately and does not come with possible design manifestations (i.e. characteristics) and guiding questions. This research aims at identifying common process design dimensions together with potential characteristics to support its exploration. Thus, it aims at providing explicit ontological guidance during the to-be process design creation to identify and explore possible redesign alternatives. It thereby contributes to the group of alternative-based redesign approaches, which are opportunity-driven in nature.

\section{Research method}

\subsection{Taxonomy development}

For the derivation of process design dimensions within the BPD-Space, we use the similarities between the design space concept and taxonomies. A taxonomy provides a systematic structure and organization to the body of knowledge in a certain field (Glass and Vessey, 1995; Nickerson et al., 2013). This structure builds on a set of dimensions with underlying 
BPMJ 27,8

characteristics (Nickerson et al., 2013). A taxonomy does not describe objects of interest in full detail but provides explanations that are useful about the object's nature (Nickerson et al., 2013). Similarly, process design dimensions aim to structure and organize the design space of process redesign alternatives. Process design dimensions are meant to be a useful (and not necessarily complete) collection for the purpose of exploring redesign alternatives. The design choices associated with design dimensions should be exhaustive, i.e. every process has a certain design manifestation in each dimension. This property aligns with the definition of collective exhaustion of taxonomy characteristics (Nickerson et al., 2013). To emphasize this aspect and to align with the terminology of the taxonomy development method, we will refer to the design choices within a design dimension as (potential) characteristics of a dimension.

We use these conceptual similarities to systematically derive the BPD-Space by following the method for taxonomy development by Nickerson et al. (2013). This method starts by determining a meta-characteristic that functions as the basis for the later selection of taxonomy dimensions and characteristics. The selection of this meta-characteristic is based on the purpose of the taxonomy and its intended use. Then, the taxonomy development method suggests proceeding iteratively by deriving dimensions and characteristics through a conceptual-to-empirical (deductive) or an empirical-to-conceptual (inductive) approach until the predefined ending conditions are met.

\subsection{Definition of meta-characteristic and ending conditions}

Starting with the taxonomy development process, we first defined the meta-characteristic. In line with our research question, our meta-characteristic is defined as changeable design elements of business processes that support the creation of redesign alternatives for business processes. Therefore, we used the internal (linked) framework elements of the BPR framework (Reijers and Liman Mansar, 2005). The BPR framework is well established in the process redesign domain. It consists of six elements to be considered in process redesign attempts and thus offers an initial set of ontological guidance on a high level of abstraction (Table 1). For this reason, the BPR framework is a suitable foundation for the purpose of this paper. Its elements cover process redesign aspects that involve the customer (internal or external) of the business process, the product/service that is generated for the customer and the business process itself (the implemented workflow and how it is executed) that generates this product/service (Reijers and Liman Mansar, 2005). The business process is linked to three more elements, namely, the participants in the business process (roles, users, groups, etc. and agents assigned to work), information used or created by the business process and technology used by the process (Reijers and Liman Mansar, 2005).

Following the taxonomy development method, it is important to determine the ending conditions that stop the development cycle. Nickerson et al. (2013) differentiate between objective and subjective ending conditions. For this research, we decided to include the following ending conditions, which will be checked together with the subjective ending conditions after each iteration. First, after the last iteration, no new dimension is identified. Second, there are no dimensions that are split or merged in the last iteration. Third, all dimensions and characteristics are unique, meaning that there exist no duplicates. To create the taxonomy, we conducted three iterations. Details are presented in Appendix 2; an overview of each iteration is provided in sections 3.3 and 3.4.

\subsection{Identification of design dimensions - conceptual-to-empirical}

First, we identified process design dimensions deductively. We started with the conceptualto-empirical approach by building on the current state of literature. Traditionally, process redesign was grounded in manufacturing logic (Miles, 2008), which is production-oriented. BPM expanded this production-focused view to a more holistic understanding of processes in 
the organizational context. Services, on the other hand, emphasize the value co-creation between a service provider and service clients (Spohrer et al., 2007). To account for these diverse ontological perspectives on process redesign, we conducted a literature review and included relevant scientific articles from the service and process redesign domain. We included artifacts (frameworks, models, etc.) that are used to describe, analyze or communicate the design of services and processes. Hence, these artifacts provide design elements of processes that are relevant for process redesign.

We considered the following artifacts. From the process literature, we include the $B P R$ framework (Reijers and Liman Mansar, 2005), the work-centered analysis (Alter, 1999) and work system framework (Alter, 2008, 2009), process meta-models (Dumas et al., 2018, p. 7; Laguna and Marklund, 2013, p. 9), the process modeling framework (Melao and Pidd, 2000), the process profile (Dumas et al., 2018, p. 52; Wagner and Patzak, 2015, p. 393) and the process canvas (Koutsopoulos and Bider, 2018). From the service domain, we included the service innovation capability framework (den Hertog et al., 2010), the digital product and service innovation framework (Nylén and Holmström, 2015), the service design planning model (Goldstein et al., 2002) and service blueprinting (Bitner et al., 2008). While we do not claim for completeness, we believe to have selected relevant literature integrating a rich view on process (and service) redesign. The taxonomy development method will complement this view through the next iterations.

We derived process design dimensions from the literature as follows. We extracted all design elements from the previously mentioned artifacts. For each design element, we identified real-life processes, which deviated from other existing processes with the same purpose through a specific manifestation of this design element. When at least two such processes were found, we kept the design element as a design dimension and investigated relevant literature for its characteristics. For instance, we identified the design dimension Customer channel, which we derived from Bitner et al. (2008), den Hertog et al. (2010) and Nylén and Holmström (2015). We then found two real-life processes, which differed from existing processes in this dimension. First, we found Webcam Social Shopper from Zugara, which enables customers to try out different clothing products virtually through an augmented reality environment (Bonetti et al., 2018). It thereby extends the traditional website-based customer channel of e-commerce. Second, we identified DocOnline, which is a digital health-care service provider in India. It offers online access to physicians through different modes of interaction, e.g. through (text, audio or video) live chat (DocOnline Health India Ltd, n.d.; Kulshrestha, 2017). It extends the traditional health-care access, which is usually bound to direct physical interaction. Details on the first iteration can be found in Appendix, Table A2.

\subsection{Identification of design dimensions - empirical-to-conceptual}

In the next step, we enriched our conceptual understanding with empirical insights. As the first objective ending condition (no new dimension has been identified) has not been met, we conducted a second iteration through the taxonomy development method. For this iteration, we went through the empirical-to-conceptual approach and inductively derived process design dimensions. Therefore, we included academic experts. We held a workshop at the end of 2019 with BPM researchers who were not involved in this research project. Five researchers participated, out of which one was a visiting associate professor and four were $\mathrm{PhD}$ candidates. We included $\mathrm{PhD}$ candidates as academic experts as all studied information systems and did their research in the field of BPM. The researchers thereby covered a wide spectrum of process-related topics and thus provided a rich academic view on business processes. In the course of the workshop, we introduced the concepts of BPD-Space and design dimensions, followed by the hitherto derived dimensions and examples from the first 
BPMJ 27,8

iteration. Based on the discussion of the existing design dimensions, we consolidated, renamed, split or deleted some dimensions. The participants also gave real-life process redesign examples, which did not fit the initial dimensions. For this reason, we added new dimensions.

We again went through the empirical-to-conceptual approach by building on the knowledge of professional process experts who are currently involved in or responsible for process redesign projects. In total, we conducted six semi-structured interviews (in one more iteration of the empirical-to-conceptual approach) at the end of 2019 with process experts from six different organizations (Appendix 1). We chose the interviewees following expert sampling (Bhattacherjee, 2012), i.e. the experts were purposefully selected from our industry network, based on their knowledge and expertise in the redesign of processes. To counter potential biases, we selected experts from various industries and different organizational sizes.

Qualitative interviews are well suited to generate rich data in explorative research, as the respondents' context is been taken into account (Schultze and Avital, 2011). All interviews were semi-structured (Myers and Newman, 2007) and consisted of four parts. In the first part of the interview, we introduced the research objective and the current state of the process design dimensions and characteristics. In the second part, we asked the experts to comment on the usefulness, understandability and completeness of the design dimensions. In the third part, we discussed the allocation of the design dimensions to the layers. In the last part, we encouraged participants to think about real-life process redesigns that were not yet covered by the existing design dimensions. By following this procedure, we accounted for the main criteria of model evaluation (Sonnenberg and Vom Brocke, 2012). After the last interview did not add new design dimensions, nor change the allocation of dimensions to layers, we felt confident that all ending conditions of the taxonomy development have been met.

\subsection{Evaluation of the artifact}

We evaluated the resulting BPD-Space in two phases. In the first phase, we used the previously gained information from the semi-structured expert interviews for a formative artificial evaluation, as the artifact was still under development (Venable et al., 2016). The interviewees thereby commented on the usefulness, understandability and completeness of the artifact's current state (Sonnenberg and Vom Brocke, 2012). We used this evaluation to further improve the artifact. Section 5.1 lists a summary of the interviews regarding the evaluation criteria and the resulting implications.

In the second phase, we validated the applicability and usefulness of the BPD-Space (Sonnenberg and Vom Brocke, 2012) by performing a summative naturalistic evaluation (Venable et al., 2016) through three real-world applications. Thereby, we conducted three halfday workshops in which the design space has been applied together with professionals from different case organizations. The workshops aimed to find alternative process designs for one pre-selected organizational process per organization. We deliberately chose organizations that differed in their context (i.e. industry, size and resources) (Brocke et al., 2016). Details on context, procedure and results of the application can be found in section 5.2. The resulting evaluation regarding applicability and usefulness is available in section 5.3.

\section{Results}

\subsection{Overall structure of the Business Process Design Space}

In this section, we lay out the derived process design dimensions, which collectively form the BPD-Space. By applying the taxonomy development method, we derived 19 dimensions. Figure 1 summarizes these dimensions and their allocation to six layers that reflect the linked 


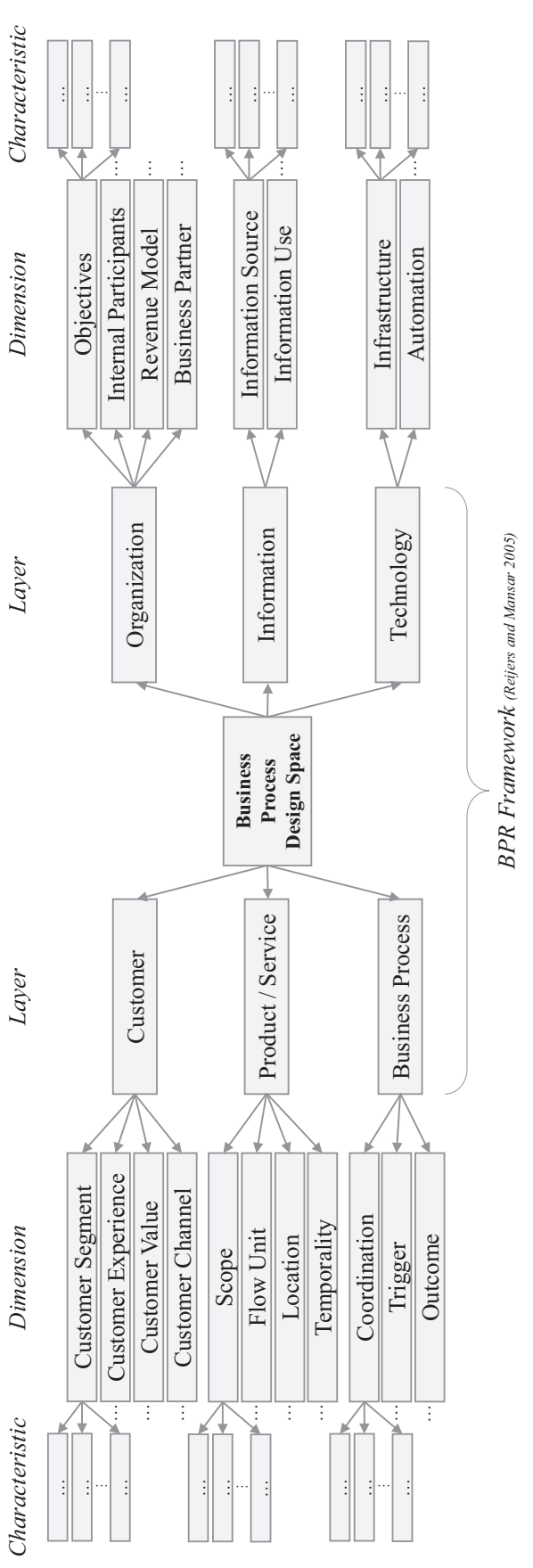

35

Figure 1. Derived BPD-Space with layers, dimensions and characteristics 
BPMJ 27,8

\section{6}

elements of the BPR framework (Reijers and Liman Mansar, 2005). In the following, we define each layer and its design dimension, list potential characteristics, guiding questions and an illustrative example, which describes how a specific characteristic manifestation has changed the process design in real-world settings. While the dimensions are supposed to be stable over time, characteristics may be added or changed for some dimensions (e.g. through the introduction of new technology). For this reason, the listed characteristics are meant to be illustrative and not exhaustive.

\subsection{Dimensions of the Business Process Design Space}

The Customer layer comprises dimensions that directly address customer needs and interactions. The layer includes four design dimensions, namely, Customer segment, Customer experience, Customer value and Customer channel, which can be found in Table 2. Customer segments categorize customers with respect to different criteria. Customer experience refers to "the internal and subjective response customers have to any direct or indirect contact with a company" (Meyer and Schwager, 2007, p. 2). Customer value refers to

\begin{tabular}{lll}
\hline Dimension & Guiding question(s) & $\begin{array}{c}\text { Customer } \\
\text { Potential characteristics }\end{array}$ \\
\hline $\begin{array}{l}\text { Customer } \\
\text { segment }\end{array}$ & How can the process & $\begin{array}{l}\text { Demographic (e.g. age, } \\
\text { deviate for different } \\
\text { occupation, gender), geographic } \\
\text { (e.g. country, region, population } \\
\text { density), psychographic (e.g. } \\
\end{array}$ \\
& lifestyle, social or personality \\
& characteristics), behavioral (e.g. \\
& purchasing, consumption or \\
& usage behavior) criteria (Kotler \\
& et al., 2012)
\end{tabular}

Customer experience

Which experience does the customer gain through the process?

Active or passive, real or virtual, mass-produced or customized, with others or alone, functional or emotional, pleasurable or arousing (Knutson and Beck, 2004)

Customer value

Customer channel
Which (additional) value can the customer receive through the process?

Functional (e.g. reduces risk, reduces costs, simplifies, quality), emotional (e.g. reduced anxiety, entertainment, rewards me), life-changing (motivation, affiliation/belonging, provides hope), and social impact (selftranscendence) (Almquist et al., 2016)

How can customers interact with the organization/process?

Functional (e.g. websites, emails, live chats), social (e.g. LinkedIn, Facebook, Foursquare),
Table 2.

Customer layer of the BPD-Space
Redesign example

Several airlines participating in Star Alliance's customer reward program Miles and More offer specialized check-in processes, depending on the previous consumption behavior of the passenger. This ranges from economy class check-in to firstclass check-in

Venmo is a social payment platform that enables its users to broadcast transactions to a public transaction feed. By doing so, it changes the (mobile) payment process from a private experience (alone) to a public experience (with others)

Various airlines introduced the option for voluntary carbon offsetting in their booking processes, e.g. Qantas Airways. By doing so, the airlines add the value "self-transcendence" by giving the option to have a social impact during the booking process community (e.g. forums and blogs), and corporate (e.g. forms, magazines, digital advertisements) (Straker et al., 2015)
DocOnline is a digital healthcare service provider in India, which offers online access to physicians through different modes of interaction, e.g. through (text, audio or video) live chat 
the positive outcome of a process or service (Dumas et al., 2018). Value can also be generated through a specific experience (Bitner et al., 2008; Knutson and Beck, 2004); thus, these two dimensions are inter-related. Whereas experience is part of every interaction (Jain et al., 2017), value refers to the perceived benefit of the customer (Goldstein et al., 2002); thus, it is not necessarily delivered to or perceived by the customer. Customers interact with the process through a customer channel (Bitner et al., 2008).

The product/service layer comprises dimensions that further define what the process offers. It includes the dimensions Scope, Flow unit, Location and Temporality (Table 3). Process Scope refers to the end-to-end perspective of the process and is mainly informed by its boundaries (Maddern et al., 2014). A Flow unit has been defined as a "transient entity that

\section{Business process design space}

\begin{tabular}{|c|c|c|c|}
\hline Dimension & Guiding question(s) & $\begin{array}{l}\text { Product/service } \\
\text { Potential characteristics }\end{array}$ & Redesign example \\
\hline Scope & $\begin{array}{l}\text { What does the customer } \\
\text { really want to achieve } \\
\text { and (how) can this be } \\
\text { integrated into the } \\
\text { process? }\end{array}$ & $\begin{array}{l}\text { Inclusion or exclusion of } \\
\text { process logic (Ramias, 2018), } \\
\text { i.e. functionalities during the } \\
\text { process execution, which can } \\
\text { be narrow or broad (Dumas } \\
\text { et al., 2018) }\end{array}$ & $\begin{array}{l}\text { The Irish low-budget airline } \\
\text { Ryanair integrated into its } \\
\text { flight booking process the } \\
\text { functionalities to acquire } \\
\text { transfers to the airport/city, get } \\
\text { parking at or close to the } \\
\text { airport and to hire a car. Thus, } \\
\text { the airline changed from a } \\
\text { narrow perspective on the } \\
\text { process (actual transport) to a } \\
\text { broad perspective (entire trip) }\end{array}$ \\
\hline
\end{tabular}

Flow unit What/who runs through the process during its execution?

Location

Where is the process executed/available? Where does it start? Where does it end?

Temporality When is the process executed/available? When does it start? When does it end?
Unit of input (e.g. a customer, patient, raw material), a unit of one or several intermediate products or components (e.g. bicycle frame in an assembly process) or a unit of output (e.g. a serviced customer or finished product) (Laguna and Marklund, 2013, p. 5)

Stationary or mobile (Gratsias et al., 2005). Stationary can be bound to a specific position (e.g. airport, train station, home) or an area (e.g. Switzerland or Italy)

Availability, execution or termination of a process at a specific point in time or timespan, e.g. a certain time of the day, week, month or a season of the year (Nivala and Sarjakoski, 2003)
Uber is a multinational ridesharing company. Despite the service of peer-to-peer ridesharing (Uber ride), the company also offers transport of food (Uber Eats) and patients (Uber Health). While the basic process of matching drivers with customers remains the same, the flow unit in this process changes (passenger, food, patients)

Austrian Airlines enables its customers to drop-off the luggage at a Viennese train station, in combination with a specific train ticket. Thus, the regular location for droppingoff the luggage changed from the airport to the train station

Domino's Pizza is a multinational food chain, which integrated an optional delivery guarantee into its delivery process. For an additional charge, the customer receives the pizza for free if the guaranteed delivery time was not met
Table 3.

Product/service layer of the BPD-Space 
BPMJ 27,8

\section{8}

proceeds through various activities and finally exits the process as finished output" (Laguna and Marklund, 2013, p. 5). Location is a key environmental context variable of processes and captures a position and its topographical information (Zhu et al., 2014). Temporality refers to the time used to specify the availability and termination of the service or to specialize its execution (e.g. through specific offers).

The Business process layer comprises dimensions that further define the operational logic of the process. It comprises three design dimensions referring to Coordination, Trigger and Outcome (Table 4). Process Coordination describes how actors, interdependent activities, goals and resources structure processes (Crowston, 1997) and thus describes how processes are set up and coordinated to meet different needs. A process Trigger is an event that starts the process execution (Dumas et al., 2018). While a channel is the medium of interaction, a trigger is

\begin{tabular}{|c|c|c|c|}
\hline Dimension & Guiding question(s) & $\begin{array}{l}\text { 1siness process } \\
\text { Potential characteristics }\end{array}$ & Redesign example \\
\hline Coordination & $\begin{array}{l}\text { How is the process } \\
\text { structured in terms of } \\
\text { activities, events and actors? } \\
\text { Should there be more/less } \\
\text { structure (for specific cases)? } \\
\text { How many variants of the } \\
\text { process exist? Is the } \\
\text { coordination transparent? }\end{array}$ & $\begin{array}{l}\text { Standard processes (single } \\
\text { variety, repetitive, binary } \\
\text { logic), routine processes } \\
\text { (limited set of variety, similar } \\
\text { but not identical repetition, } \\
\text { fuzzy logic) and non-routine } \\
\text { processes (unlimited set of } \\
\text { variety, non-repetitive, } \\
\text { interpretative logic) (Lillrank, } \\
\text { 2003) }\end{array}$ & $\begin{array}{l}\text { A standard shipping } \\
\text { process provided by UPS } \\
\text { allows customers to send } \\
\text { packages. As the address } \\
\text { can change during shipping, } \\
\text { UPS has also established } \\
\text { routine processes to change } \\
\text { an address after an order } \\
\text { has been placed. UPS also } \\
\text { offers customized solutions } \\
\text { where UPS needs to create a } \\
\text { non-routine process }\end{array}$ \\
\hline
\end{tabular}

Trigger What/who starts the process?

Outcome

What are possible ends of the process? How can we react to negative outcomes?
Table 4.

Business process layer of the BPD-Space
Message events (e.g. order is received, need is identified), temporal events (e.g. every Friday morning, every working day of the month), conditional events (a business rule is met) or signal events (a process starts another process) (Dumas et al., 2018)

Message events (e.g. package sent, loan approved), temporal events (e.g. Sunday night, two weeks after the last interaction), conditional events (a business rule is met), signal events (another process ends the process) or error events (e.g. product not available) (Dumas et al., 2018)
Amazon introduced anticipatory shipping. Based on big data analytics and artificial intelligence, the e-commerce retailer calculates a likelihood that a product is bought by a customer. Based on this likelihood, the shipping process might start even before the customer actively decides to buy the product. Instead of a message trigger initiated by the customer, another process is triggering these purchase-related procedures (signal trigger)

In the event of an unexpected delay of train or flight, Lufthansa Express Rail will change to another connection free of charge. Thus, instead of missing the connection as the process outcome, a conditional event has been added to the process 
a certain event communicated through this channel and detected by the recipient, which is followed by certain actions. Process outcomes refer to all legitimate ends of process instances (Koutsopoulos and Bider, 2018) and can be positive or negative (Dumas et al., 2018). While positive outcomes deliver value, negative outcomes do not (Koutsopoulos and Bider, 2018).

The Organization layer comprises dimensions that define the strategic organization of the process. It includes the design dimensions Objectives, Internal participants, Revenue model and Business partners (Table 5). Objectives are derived from the organization's vision and strategy and can be refined by performance measures (Dumas et al., 2018). Objectives depend on each other by either complementing or conflicting with each other. Process participants refer to anyone who is directly or indirectly involved in the execution of the process (Alter, 2013).

\section{Business process design space}

\begin{tabular}{|c|c|c|c|c|}
\hline Dimension & Guiding question(s) & $\begin{array}{c}\text { Organization } \\
\text { Potential characteristics }\end{array}$ & Redesign example & \\
\hline Objectives & $\begin{array}{l}\text { How do we define and } \\
\text { measure process } \\
\text { success? What do we } \\
\text { want to achieve with } \\
\text { the process in terms of } \\
\text { objectives? }\end{array}$ & $\begin{array}{l}\text { Financial (e.g. return on capital, } \\
\text { shareholder value), customer (e.g. } \\
\text { image and reputation, customer } \\
\text { relationships), internal processes } \\
\text { (e.g. improvement of products, } \\
\text { services and processes regarding } \\
\text { quality, time, or flexibility), } \\
\text { learning and growth (e.g. } \\
\text { technology leadership, employee } \\
\text { capabilities), trust (Dumas et al., } \\
\text { 2018; Kaplan and Norton, 1993; } \\
\text { Rosemann, 2019) }\end{array}$ & $\begin{array}{l}\text { Amazon aims to strengthen the } \\
\text { trust of its customers within its } \\
\text { purchasing process by having } \\
\text { the customer re-confirming the } \\
\text { desire to order if the same item } \\
\text { is ordered for the second time. It } \\
\text { thus follows the objective to be } \\
\text { perceived as valid and reliable, } \\
\text { such that a positive attitude } \\
\text { toward the organization is } \\
\text { embraced (Rosemann, 2019) }\end{array}$ & \\
\hline $\begin{array}{l}\text { Internal } \\
\text { participants }\end{array}$ & $\begin{array}{l}\text { Who is doing what } \\
\text { during the process } \\
\text { execution? }\end{array}$ & $\begin{array}{l}\text { Process responsibilities (e.g. } \\
\text { process owner, process } \\
\text { managers), competencies or } \\
\text { disciplinary responsibilities of } \\
\text { activities (e.g. for the allocation of } \\
\text { resources or legal matters) } \\
\text { (Lohmann and zur Muehlen, } \\
\text { 2015) }\end{array}$ & $\begin{array}{l}\text { Emergency services are } \\
\text { increasingly using apps that } \\
\text { notify registered users about } \\
\text { close-by emergencies (e.g. } \\
\text { cardiac attack). Qualified } \\
\text { persons who use the app (e.g. } \\
\text { nurses) are included in the } \\
\text { emergency process to } \\
\text { administer first aid before } \\
\text { paramedics arrive }\end{array}$ & \\
\hline $\begin{array}{l}\text { Revenue } \\
\text { model }\end{array}$ & $\begin{array}{l}\text { How/where can we } \\
\text { generate revenue } \\
\text { (differently)? }\end{array}$ & $\begin{array}{l}\text { Revenue techniques (e.g. } \\
\text { advertising-, commission- or } \\
\text { licensing-based revenue logics) } \\
\text { and revenue sources (e.g. new } \\
\text { revenue models through } \\
\text { digitalization) (Veit et al., 2014) }\end{array}$ & $\begin{array}{l}\text { In the UK-based café chain } \\
\text { ZIFERBLAT, customers pay } \\
\text { for the time spent in the venue } \\
\text { and not for their consumption. } \\
\text { While the underlying process } \\
\text { remains similar, the revenue } \\
\text { model changed }\end{array}$ & \\
\hline $\begin{array}{l}\text { Business } \\
\text { partner }\end{array}$ & $\begin{array}{l}\text { Which parts of the } \\
\text { process can we } \\
\text { outsource/insource? }\end{array}$ & $\begin{array}{l}\text { Suppliers (delivering materials or } \\
\text { services to be further processed), } \\
\text { intermediaries (agents between } \\
\text { organization and customers), and } \\
\text { alliance partners (producing } \\
\text { complementary products or } \\
\text { services) (Parker et al., 2016; } \\
\text { Saxena and Bharadwaj, 2009) }\end{array}$ & $\begin{array}{l}\text { With its well-developed } \\
\text { infrastructure, Amazon } \\
\text { supports producers of books by } \\
\text { acting as an intermediary in the } \\
\text { purchasing process between } \\
\text { producers (e.g. independent } \\
\text { writers) and customers; thus, } \\
\text { the activities related to sales, } \\
\text { marketing and distribution are } \\
\text { outsourced to the business } \\
\text { partner (Amazon) }\end{array}$ & $\begin{array}{r}\text { Table } 5 . \\
\text { Organization layer of } \\
\text { the BPD-Space }\end{array}$ \\
\hline
\end{tabular}


BPMJ 27,8

40

Internal participants contribute to value creation as they bring in different competencies and skills and take over responsibilities in process work. The Revenue model refers to the business logic to turn customer value into revenues. Digitalization leads to new opportunities to gain revenue, e.g. through platform ecosystems (Parker et al., 2016). According to Anthony et al. (2019), digitalization enables organizations to open up additional sources for revenue that exist side-by-side the business core. Finally, Business partners are external partners that are involved in the process but are not subordinated to the organization (Dumas et al., 2018). For example, organizations outsource certain activities that are carried out by partners (e.g. shipping products).

The Information layer comprises dimensions that focus on the integration and use of information (Table 6). It includes the design dimension Information source, which refers to the origin of data integrated into processes. The second dimension, Information usage, captures how data can contribute to (new) value creation for the customer or to the business value of the organization.

The Technology layer focusses on dimensions that address the use of software and hardware to support the process. In light of the advent of sophisticated digital technologies, this layer has been receiving increasing attention (Breuker et al., 2016). As technology is an enabler for many dimensions within the design space (e.g. new customer channels), we introduce two design dimensions, namely, Infrastructure and Automation (Table 7). On the one hand, technologies can be used to provide Infrastructures enabling the execution of the process. On the other hand, technology can be used for Automation purposes (van der Aalst et al., 2018), i.e. "hardware/software configurations that perform totally automated activities" (Alter, 2013). In this context, specific activity sequences or parts of the process are being automated by technologies.

\section{Evaluation of the Business Process Design Space}

To evaluate the BPD-Space, we conducted a formative artificial evaluation (Venable et al., 2016) through interviews with process experts while the artifact was still under development

\begin{tabular}{|c|c|c|c|}
\hline Dimension & Guiding question(s) & $\begin{array}{c}\text { Information } \\
\text { Potential characteristics }\end{array}$ & Redesign example \\
\hline $\begin{array}{l}\text { Information } \\
\text { source }\end{array}$ & $\begin{array}{l}\text { How can we integrate } \\
\text { new/different data } \\
\text { into the process? }\end{array}$ & $\begin{array}{l}\text { Internal (existing or self- } \\
\text { generated) or external (acquired, } \\
\text { customer provided, free } \\
\text { available; e.g. social media or } \\
\text { web-crawled) (Hartmann et al., } \\
\text { 2014) }\end{array}$ & $\begin{array}{l}\text { Social media analysis } \\
\text { providers, such as Awario, } \\
\text { enable organizations to } \\
\text { monitor customer satisfaction, } \\
\text { brand reputation and other } \\
\text { indicators in real-time through } \\
\text { publicly shared social media } \\
\text { posts. Thus, organizations do } \\
\text { not solely depend on directly } \\
\text { customer provided data }\end{array}$ \\
\hline $\begin{array}{l}\text { Information } \\
\text { usage }\end{array}$ & $\begin{array}{l}\text { How can we use the } \\
\text { information collected/ } \\
\text { gathered in the } \\
\text { process? }\end{array}$ & $\begin{array}{l}\text { Generation (crawling, } \\
\text { crowdsourcing), processing, } \\
\text { analytics (descriptive, predictive, } \\
\text { prescriptive), visualization, } \\
\text { distribution of process data } \\
\text { (Hartmann et al., 2014) }\end{array}$ & $\begin{array}{l}\text { US-based The Weather } \\
\text { Company is primarily } \\
\text { concerned with weather } \\
\text { forecasts. It started to sell } \\
\text { weather data to retailers and } \\
\text { advertisers, enabling them to } \\
\text { apply weather-based selling } \\
\text { strategies (e.g. Walmart can } \\
\text { increase the stock of rain } \\
\text { protection gear or adjust } \\
\text { prices) }\end{array}$ \\
\hline
\end{tabular}

Table 6.

Information layer of the BPD-Space
Generation (crawling, prescriptive), visualization, distribution of process data (Hartmann et al., 2014)
Social media analysis enable organizations to monitor customer satisfaction, brand reputation and other indicators in real-time through publicly shared social media not solely depend on directly

US-based The Weather forecasts. It started to sell weather data to retailers and advertisers, enabling them to apply weather-based selling strategies (e.g. Walmart can protection gear or adjust prices) 


\begin{tabular}{|c|c|c|c|c|}
\hline Dimension & Guiding question(s) & $\begin{array}{c}\text { Technology } \\
\text { Potential characteristics }\end{array}$ & Redesign example & $\begin{array}{r}\text { Business } \\
\text { process }\end{array}$ \\
\hline Infrastructure & $\begin{array}{l}\text { Which software or } \\
\text { hardware could support } \\
\text { the process' execution } \\
\text { and in what ways? }\end{array}$ & $\begin{array}{l}\text { Ability to support process- } \\
\text { related needs, e.g. by } \\
\text { monitoring work-related } \\
\text { activities and events (e.g. } \\
\text { different BPMS solutions) } \\
\text { (Pourmirza et al., 2017) or } \\
\text { storing, distributing and } \\
\text { searching relevant } \\
\text { information (e.g. different } \\
\text { ECMS solutions) } \\
\text { (Jaakonmäki } \text { et al., 2018) }\end{array}$ & $\begin{array}{l}\text { Process management solutions, } \\
\text { e.g. Signavio Process Manager, } \\
\text { support organizations to model, } \\
\text { communicate, execute and } \\
\text { monitor their business } \\
\text { processes }\end{array}$ & 41 \\
\hline Automation & $\begin{array}{l}\text { How can event detection, } \\
\text { activity execution or } \\
\text { information exchange of } \\
\text { the process be } \\
\text { automated? }\end{array}$ & $\begin{array}{l}\text { Sensors to detect start, } \\
\text { intermediate and end events } \\
\text { (e.g. temperature or } \\
\text { movement sensors), activity } \\
\text { automation (e.g. machine } \\
\text { learning, natural language } \\
\text { processing, robotic process } \\
\text { automation), information } \\
\text { exchange (e.g. RFID, NFC, } \\
\text { barcodes) }\end{array}$ & $\begin{array}{l}\text { IBM Watson Explorer is used } \\
\text { by insurance companies to } \\
\text { analyze structured and } \\
\text { unstructured data associated } \\
\text { with insurance claims. Based on } \\
\text { machine learning, Watson } \\
\text { Explorer gives } \\
\text { recommendations on whether a } \\
\text { claim is eligible and to what } \\
\text { extent the damage should be } \\
\text { covered. It thus semi-automates } \\
\text { the insurance claim handling } \\
\text { process }\end{array}$ & $\begin{array}{r}\text { Table } 7 . \\
\text { Technology layer of } \\
\text { the BPD-Space }\end{array}$ \\
\hline
\end{tabular}

(Section 5.1). Additionally, we evaluated its applicability and usefulness through three realworld applications in different organizations (sections 5.2 and 5.3). We thereby covered evaluation activities associated with a summative naturalistic evaluation (Venable et al., 2016).

\subsection{Insight from the expert interviews}

Through the expert interviews, we gained the following insights. Regarding usefulness, all practitioners deemed the BPD-Space as a valuable artifact during process redesign projects. One expert specifically mentioned that the approach is "very helpful in the course of actual consulting projects." Two of the six process experts pointed out that it is not clear which dimension to focus on during redesign projects in their respective organizations, and that the derived dimensions may be too detailed for top management considerations. Two process experts who consult external clients mentioned that the dimensions to focus on in actual consulting projects are determined by the scope of the project, which should be defined before applying the BPD-Space. Some dimensions were also deemed as rather strategic management considerations, which might not be part of every process redesign project. One expert mentioned that the dimensions to consider in redesign projects mainly depend on "the strategic importance of the redesign project within the organization and the people involved in the project." The experts recommended that additional guidance on the application of the BPD-Space would be useful. We responded to this comment by offering application guidelines in section 6.2.

The professional process experts also evaluated the understandability and completeness of the approach. Regarding understandability, one expert proposed to change the representation of the dimensions, such that layers, dimensions and characteristics are visible in one 
BPMJ 27,8

summarizing representation. We included this consideration for our representation of the design space (Figure 1). All experts commented that the underlying idea behind the design space is understandable. One expert found the given redesign examples valuable for understanding the design dimensions. Regarding completeness, three experts proposed the introduction of new characteristics. This feedback has been incorporated into the resulting design space. Overall, the BPD-Space and its underlying idea have been found to be a novel and stimulating approach for process redesign.

\subsection{Real-world applications}

We conducted three real-world applications. The corresponding organizations were a financial technology startup, a large-scale medical diagnostic organization and a mid-sized transmission system operator. All organizations are headquartered in Central Europe. This set of organizations allowed us to evaluate the design space in a variety of industry contexts. We started all workshops by explaining the research context, the underlying idea behind the design space concept and the BPD-Space. Consecutively, we presented the design dimensions. One at a time, we introduced the respective dimension and applied it to the process of the case organization. The participants explored how the respective design dimension is currently represented. Subsequently, they identified other potential characteristics (i.e. design manifestations of the design dimension in focus) and used them for the creation of to-be process ideas. The first design dimension was in the customer layer, and we further proceeded by considering the participant's interest until the allocated time for the idea creation was over. In what follows below, we describe the case organizations, the process in focus and the resulting redesign ideas. Appendix 3 offers a list of additional redesign ideas that were created throughout the three workshops.

5.2.1 Application 1 - financial technology startup. We conducted the first real-world application with the financial technology startup baningo (Baningo, 2020). The chief executive officer (CEO) as well as the head of customer relations of baningo participated. We focused on "baningo-select," which is a service that supports customers in finding appropriate financial advisors through matching algorithms. The platform thereby mediates between clients and financial advisors, e.g. by providing a tool to schedule appointments, and through data protection compliant text and video chat functionalities. The service can be embedded in the website of financial institutions (e.g. banks). Roughly speaking, the process commences after a customer provides initial information online before being matched with a financial advisor.

During the workshop, the participants used nine design dimensions and created 14 redesign ideas. For instance, the application of the outcome design dimension (which refers to alternative process endings) led to the creation of two redesign ideas; one was to recommend another financial advisor to the customer in case an ongoing consultation did not solve a specific customer need or if the customer was unhappy with the quality of the consultation. Therefore, the customer should have the option to indicate the perceived satisfaction after each consultation. Based on this information, an alternative advisor can be recommended by the system, if required and available. The other idea was to recommend other advisors to the customer in case the customer moves to a different location. Both design ideas were not covered by the current process.

5.2.2 Application 2 - large-scale medical diagnostic organization. The second case organization was Labnetic (pseudonym). Labnetic is a globally operating large-scale organization specialized in medical diagnostics. In this workshop, the global business process manager and process owner participated. The process in focus was the preventive maintenance process for medical diagnostic instruments of business customers, e.g. molecular diagnostics devices for medical laboratories. It comprised activities related to 
scheduling, planning and executing the maintenance of devices. Labnetic contacts its customers on a regular basis to schedule appointments. The back office then assigns an available service engineer to conduct the maintenance at the customer's site.

The participants used 13 design dimensions and developed 18 redesign ideas for the maintenance process. For example, the design dimension customer segment (i.e. to differ the process based on specific customer characteristics) led to two ideas. One was to segment the customers based on location accessibility. To effectively serve remote customers (e.g. in rural areas), the process should have an additional activity that is concerned with permanently checking the travel costs (e.g. flight fares). The customers then receive possible maintenance dates, when travel costs were identified as comparably low. The second idea was to segment customers based on downtime flexibility of the device(s) to be maintained. Less flexible customers should thereby be offered a wider range of possible maintenance dates from which they could choose. This is expected to result in fewer iterations for finding an appropriate date.

5.2.3 Application 3-mid-sized transmission system operator. The third application of the BPD-Space took place with ELECTRO (pseudonym), a mid-sized transmission system operator. The company is responsible for controlling, operating and maintaining the transmission system for electrical power. The head of process management and a business process manager of the organization participated in the workshop. The participants decided to focus on a core process, namely, the provision of a new grid connection process for end customers. Roughly speaking, the process entails that a customer contacts ELECTRO and provides initial information. Once an order is signed, it is saved in the organizational SAP system and the construction plans are created. These are then forwarded to a contracting company. The contracting company independently arranges an appointment with the customer and carries out the task. Once the new grid connection is provided, ELECTRO pays the contracting company, bills the customer and files a completion report for the new grid connection.

For the new grid connection process of ELECTRO, ten redesign ideas were created based on eight design dimensions. One process redesign idea emerged from the reflection on the dimension trigger. The idea was to (optionally) remind the customer through email or phone to apply for a new grid connection once the construction site power supply has been granted. The construction site power supply is usually required for the construction work, but it is independent of the subsequent connection of the household to the transmission system. The reminder would help to avoid late grid connection applications by using an earlier encounter with the customer to initiate the process. Another redesign idea was developed with the design dimension information source. The contracting company gathers status information about arrangements, plans and problems between the third party and the customer. This information is not shared with ELECTRO in the current process. The information can then be used to send the customer a reminder about upcoming construction work on the site and to have all information gathered in the customer portal as a single source of documentation.

\subsection{Applicability and usefulness}

As for applicability, practitioners from all real-world applications found the BPD-Space suitable for the generation of redesign alternatives. Workshop participants from baningo noted that once an alternative characteristic manifestation of a design dimension has been identified, it can be challenging to move on to another potential characteristic. Furthermore, we observed that generated redesign ideas sometimes affect more than one design dimension. For instance, a new information source may also be used as a trigger. We also found that we can use design dimensions of a previously generated redesign idea to jump between the design dimensions, instead of iterating through all dimensions consecutively. The guiding 
BPMJ 27,8

questions and potential characteristics were perceived as particularly helpful to understand the direction and intention of a design dimension. Labnetic and baningo both reported that these are important to understand and apply the dimensions in a given context. In general, the practitioners found the design dimensions to be more suitable for generating redesign alternatives compared to process model representations, as it abstracts from "irrelevant implementation details" and does not require process modeling knowledge (Labnetic).

As for usefulness, baningo found the BPD-Space "very supportive" during the creation of process redesign alternatives, as it "supported the structured analysis of the process through different perspectives." Participants from the first two workshops considered the majority of generated redesign alternatives useful and feasible for future changes to the process. This indicates that the BPD-Space helps create adequate redesign alternatives. ELECTRO noted that the BPD-Space provides a "good guideline to completely screen a process in various respects," especially for less prominent processes in the organization. The practitioners also noted that it was challenging to find entirely new process designs for the new grid connection process. This might be due to the specific context of ELECTRO. As a monopolist, it needs to account for a high number of regulations that limit the number of alternatives within the design space. In a similar vein, participants from baningo noted that some constraints have been disregarded during the creation of redesign alternatives, which may make some redesign ideas less likely to be implemented in the near future. In general, the BPD-Space has been perceived to trigger the creation of more ambitious ideas by thinking into directions that would have been disregarded in regular brainstorming sessions. In this regard, it helps as a "mental liberation" (baningo) to break out of normal thought patterns and constraints. Labnetic noted that the design dimensions helped to shift the focus away from technologycentered redesign ideas, indicating that most of their redesign initiatives usually focus on technology-related dimensions, but tend to exclude most other dimensions.

\section{Discussion}

\subsection{Implications for research and practice}

In the following, we will discuss the implications that follow from this research. First and foremost, we provide comprehensive ontological guidance during the to-be process creation. While existing approaches provide important reference points to look at processes (e.g. Reijers and Mensa, 2005), we zoom into the underlying dimensions and characteristics. Thereby, we direct designers' attention to various aspects that are part of a specific process but might not be explicitly considered. This can be the case, for example, when specific components of a process are taken for granted and are not questioned during redesign activities. Hence, the BPD-Space can be used to explore, question and rethink a process in various respects. This work reflects the first attempt to organize and synthesize the various dimensions and underlying characteristics involved in process redesign.

Exploring the BPD-Space also provides initial procedural guidance for the creation of process redesign alternatives. Existing redesign methods provide structure for the overall redesign project, but have hardly shown to provide directions during the to-be process creation. Exploring the BPD-Space, e.g. in a workshop setting, also comes with initial procedural guidance for the creation of alternative to-be process designs. Building on the idea of design space analysis (Maclean et al., 1991), users of the design space can iterate through its dimensions and use the guiding questions to analyze current and alternative characteristic manifestations. By combining different manifestations, alternative process designs can thereby be generated. However, while our application guidelines support the procedural perspective, a method for providing full procedural guidance is yet to be developed.

It is important to note that the BPD-Space is not competing with but complementing existing process redesign approaches. Existing methods and techniques use different 
rationales for the redesign endeavor (Table 1). The BPD-Space can be a valuable means to create to-be processes during the redesign phase of other redesign methods, e.g. in the course of interaction-based approaches like NESTT (Rosemann, 2017). It can also be applied in conjunction with other techniques of process redesign, e.g. with pattern-based approaches like the explorative process design patterns (Rosemann, 2020). The BPD-Space itself can be classified into the group of alternative-based redesign approaches, as it aims to identify and explore a wide range of process design alternatives. It thereby builds on and extends the BPR framework (Reijers and Liman Mansar, 2005), while it also provides a language for applying the process grammar (Lee et al., 2008).

The BPD-Space abstracts from specific process flows and representations of processes. It thereby enables an unconstrained exploration of various alternative process designs. Users of the process dimensions are not influenced (or limited) in their thinking by detailed process descriptions, as in form of process models. Research on nudging, and digital nudging in specific, has shown that human thinking and human choice is significantly influenced by the way information about choice is presented (Weinmann et al., 2016). By abstracting from the inner flow and details of a process but highlighting the design dimensions instead, it stands to reason that process designers are nudged more toward thinking ways of conducting a process that is influenced less by the current practice of conducting a process, so in other words, to find more innovative ways of conducting a process.

The BPD-Space can be used to realize explorative BPM. Following recent claims that BPM activities should become more ambidextrous (Grisold et al., 2019; Rosemann, 2020), we argue that the proposed BPD-Space can serve as a starting point for exploration, i.e. to identify new opportunities for organizations. Here, it is important to highlight the distinction between design dimensions and characteristics. The design dimensions we have identified are meant to be stable over time. However, new characteristics may emerge and change, e.g. due to new developments and innovations. Thereby, design dimensions can serve as a means to scan and categorize dynamics in an organization's environment and to translate them into concrete implications for processes (Grisold et al., 2019). This holds especially for the technology layer, where continuous research and development lead to new technological features.

Finally, the BPD-Space allows exploring design alternatives for different types of processes. Research on the role of context has found that processes differ regarding various characteristics, such as variability, repetitiveness or uncertainty (Brocke et al., 2016). While most of the process design research has focused on well-structured and repetitive processes, the need for process design in organizations, however, is rather in the non-repetitive, knowledge-intensive and creative processes. In this regard, the BPD-Space provides a means to explore design alternatives thinking out of the box across all processes types, which is highly needed in practice.

\subsection{Guidelines for application}

The three real-world applications of the BPD-Space demonstrated its potential for the exploration of process redesign alternatives. To support future users, we provide the following guidelines for applying the BPD-Space based on our insights from the formative and summative evaluation:

(1) Ahead of iterating through and applying the design dimensions, determine which dimensions are especially useful in the context of the application (e.g. based on the goal of the redesign endeavor) and focus on these. Context-based constraints might also cause the exclusion of design dimensions.

(2) Predefine specific time slots (e.g. $20 \mathrm{~min}$ for each design dimension) to ensure a wide coverage of design dimensions and to prevent idea fixation. Make adequate breaks to ensure mental focus and creativity. 
BPMJ

27,8

(3) When applying the BPD-Space, first allow for and encourage an unconstraint creation of redesign ideas before prioritizing these according to weighted evaluation criteria (e.g. feasibility, viability and desirability).

(4) In the course of a workshop, provide a visual representation of the BPD-Space to navigate through the workshop and to provide a shared understanding and language. Allocating the layers to different walls of the room can further support the interaction during a workshop.

(5) To prevent a potential anchoring effect around the first redesign idea of a design dimension, aim to apply more than one characteristic within one design dimension.

(6) To prevent a potential anchoring effect and to adapt the BPD-Space to the context of its application, explore other potential characteristics (i.e. design manifestations of dimensions) for each design dimension, which are not yet mentioned in the BPDSpace.

(7) For each generated redesign idea, note which design dimensions are affected to detect if a wide range of the design space is covered (or which design dimensions are underrepresented).

(8) In a workshop setting, break out into sub-groups when generating redesign ideas to cover a wider range of ideas, if group size allows.

\subsection{Limitations and future research}

Our research comes with limitations. First, design dimensions do not aim for completeness but have to be useful for an intended purpose and audience, similar to dimensions in taxonomies (Nickerson et al., 2013). Although the derived BPD-Space has been evaluated as useful by professional process experts and in the course of three real-world applications, there might be application scenarios in which additional design dimensions could be helpful. In line with the extendibility requirement of taxonomy development (Nickerson et al., 2013), the design space should be continuously challenged and further developed by future applications and research. Second, the derived design dimensions are implementation-independent, i.e. rather abstract design considerations. The actual implementation (on a process model level) of a specific manifestation of design dimensions can take various forms and is again a creative task. We find this abstraction useful to detach from process model-specific constraints and biases. However, the interrelation of design dimensions and process models is not yet researched.

We see two main avenues for future research. On the one hand, descriptive research is required to explore how and under which circumstances the use of design dimensions can lead to innovative design outcomes. For example, it should be investigated if there are contexts where the use of these dimensions is more valuable than in others or if there are dominant strategies to combine or reconfigure specific dimensions. On the other hand, despite our application guidelines, prescriptive research should evaluate and propose how these dimensions should be used in redesign projects. While the BPD-Space provides a comprehensive ontological perspective on the creation of process redesign alternatives, it only offers moderate procedural guidance. Therefore, it should be investigated how a method can systematically guide through the BPD-Space and which dimensions should be emphasized taking into consideration the context of the redesign project. This also includes guidance on how to integrate the BPD-Space into existing process redesign approaches. Additionally, evaluation criteria should be defined to prioritize the high number of resulting redesign alternatives (Nygren et al., 2017). Overall, we call for future research in the area of systematic creation of process design alternatives to foster improvement and innovation of processes. 


\section{Conclusion}

Following recent calls to support the systematic redesign of processes (Grisold et al., 2019; Gross et al., 2019; Zellner, 2011), we defined the BPD-Space for systematically exploring the design space of processes and, in this way, address the challenges associated with the to-be process design creation (Grisold et al., 2019; Sharp and Mcdermoot, 2009, p. 323; Vanwersch et al., 2015; Zellner, 2011). Accordingly, to facilitate the exploration of alternative process designs, we developed the BPD-Space, which is structured into six layers and 19 corresponding dimensions, complemented by various characteristics and guiding questions. To derive these design dimensions, we made use of the taxonomy development method provided by Nickerson et al. (2013) and synthesized both, knowledge from the academic literature and knowledge from practitioners. We evaluated the usefulness and applicability of the approach by three real-world applications according to evaluation guidelines (Venable et al., 2016). The BPD-Space fills a gap of process redesign research by providing ontological and procedural guidance during the actual act of creating new to-be process designs. It also offers concrete guidance for practitioners who undertake redesign activities to break out of conventional thinking.

\section{References}

Afflerbach, P., Hohendorf, M. and Manderscheid, J. (2017), "Design it like Darwin - a value-based application of evolutionary algorithms for proper and unambiguous business process redesign", Information Systems Frontiers, Vol. 19 No. 5, pp. 1101-1121.

Almquist, E., Senior, J. and Bloch, N. (2016), "The elements of value", Harvard Business Review, September, pp. 46-53.

Alter, S. (1999), Information Systems: A Management Perspective, 3rd ed., Addison Wesley, Massachusetts.

Alter, S. (2008), "Defining information systems as work systems: implications for the IS field", European Journal of Information Systems, Vol. 17 No. 5, pp. 448-469.

Alter, S. (2009), "Metamodel for understanding, analyzing, and designing sociotechnical systems", Proceedings of JAIS Theory Development Workshop. Sprouts: Working Papers on Information Systems, Vol. 9, p. 59.

Alter, S. (2013), "Work system theory: overview of core concepts, extensions, and challenges for the future", Journal of the Association of Information Systems, Vol. 14 No. 2, pp. 72-121.

Anthony, S.D., Trotter, A. and Schwartz, I.E. (2019), "The top 20 business transformations of the last decade”, Harvard Business Review September, available at: https://hbr.org/2019/09/the-top-20business-transformations-of-the-last-decade (accessed 21 November 2019).

Baningo (2020), "Baningo-select", available at: https://baningo-select.com/ (accessed 21 July 2020).

Bettencourt, L.A., Brown, S.W. and Sirianni, N.J. (2013), "The secret to true service innovation", Business Horizons, Kelley School of Business, Indiana University, Vol. 56 No. 1, pp. 13-22.

Beverungen, D., Buijs, J.C.A.M., Becker, J., Di Ciccio, C., van der Aalst, W.M.P., Bartelheimer, C., vom Brocke, J., Comuzzi, M., Kraume, K., Leopold, H., Matzner, M., Mendling, J., Ogonek, N., Post, T., Resinas, M., Del-Rio-Ortega, A., La Rosa, M., Santoro, F., Solti, A., Song, M., Stein, A., Stierle, M. and Wolf, V. (2020), "Seven paradoxes of business process management in a hyper-connected world", Business and Information Systems Engineering. doi: 10.1007/s12599-020-00646-z.

Bhattacherjee, A. (2012), Social Science Research: Principles, Methods, and Practices, 2nd ed., Global Text Project, Florida.

Bitner, M.J., Ostrom, A.L. and Morgan, F.N. (2008), "Service blueprinting: a practical technique for service innovation”, California Review Management, Vol. 50 No. 3, pp. 65-94.

Bonetti, F., Warnaby, G. and Quinn, L. (2018), "Augmented reality and virtual reality in physical and online retailing: a review, synthesis and research agenda", in Jung, T. and Tom Dieck, M.C. (Eds), 
BPMJ 27,8

Augmented Reality and Virtual Reality: Empowering Human, Place and Business, Springer International Publishing, Cham, pp. 119-132.

Bortolotti, T. and Romano, P. (2012), "Lean first, then automate': a framework for process improvement in pure service companies. A case study", Production Planning and Control, Vol. 23 No. 7, pp. 513-522.

Breuker, D., Matzner, M., Delfmann, P. and Becker, J. (2016), "Comprehensible predictive models for business processes”, MIS Quarterly, Vol. 40 No. 4, pp. 1009-1034.

Brinkkemper, S. (1996), "Method engineering: engineering of information methods and tools", Information and Software Technology, Vol. 38, pp. 275-280.

vom Brocke, J., Zelt, S. and Schmiedel, T. (2016), "On the role of context in business process management", International Journal of Information Management, Elsevier, Vol. 36 No. 3, pp. $486-495$.

Brocke, J., Denner, M.S., Schmiedel, T., Stelzl, K., Röglinger, M. and Wehking, C. (2020), "Contextaware business process management method assessment and selection", Business and Information Systems Engineering, Vol. 62, pp. 1-24.

Crilly, N. and Cardoso, C. (2017), "Where next for research on fixation, inspiration and creativity in design?”, Design Studies, ACM Press, New York, New York, USA, Vol. 50, pp. 1-38.

Crowston, K. (1997), “A coordination theory approach to organizational process design”, Organization Science, Vol. 8 No. 2, pp. 157-176.

Davenport, T.H. and Short, J.E. (1990), "The new industrial engineering - information technology and business process redesign”, Sloan Management Review, Vol. 31 No. 4, pp. 11-27.

den Hertog, P., van der Aa, W. and de Jong, M.W. (2010), "Capabilities for managing service innovation: towards a conceptual framework", Journal of Service Management, Vol. 21 No. 4, pp. 490-514.

Denner, M.S., Püschel, L.C. and Röglinger, M. (2018), "How to exploit the digitalization potential of business processes”, Business and Information Systems Engineering, Vol. 60 No. 4, pp. 331-349.

DocOnline Health India Ltd. (n.d.), "How DocOnline doctor consultation works | audio/video/chat with certified doctors", available at: https://www.doconline.com/how-it-works (accessed 4 November 2019).

Dove, G., Hansen, N.B. and Halskov, K. (2016), “An argument for design space reflection”, Proceedings of the 9th Nordic Conference on Human-Computer Interaction - NordiCHI '16, ACM Press, New York, USA, Vols 23-27 Octo, pp. 1-10.

Dumas, M., La Rosa, M., Mendling, J. and Reijers, H.A. (2018), Fundamentals of Business Process Management, 2nd ed., Springer Berlin Heidelberg, Berlin, Heidelberg. doi: 10.1007/978-3-66256509-4.

Figl, K. and Recker, J. (2016), "Process innovation as creative problem solving: an experimental study of textual descriptions and diagrams", Information and Management, Vol. 53 No. 6, pp. 767-786.

Frank, L., Poll, R., Roeglinger, M. and Lea, R. (2020), "Design heuristics for customer-centric business processes”, Business Process Management Journal, Vol. 26 No. 6, pp. 1283-1305, doi: 10.1108/ BPMJ-06-2019-0257.

Glass, R.L. and Vessey, I. (1995), “Contemporary application-domain taxonomies”, IEEE Software, Vol. 12 No. 4, pp. 63-76.

Goldstein, S.M., Johnston, R., Duffy, J.A. and Rao, J. (2002), "The service concept: the missing link in service design research?", Journal of Operations Management, Vol. 20 No. 2, pp. 121-134.

Gratsias, K., Frentzos, E., Delis, V. and Theodoridis, Y. (2005), “Towards a taxonomy of location based services", Lecture Notes in Computer Science (Including Subseries Lecture Notes in Artificial Intelligence and Lecture Notes in Bioinformatics), Vol. 3833 LNCS, Springer-Verlag, Berlin Heidelberg, pp. 19-30. 
Grisold, T., Gross, S., Röglinger, M., Stelzl, K. and vom Brocke, J. (2019), "Exploring explorative BPM setting the ground for future research", 2019 Proceedings 17th International Conference BPM2019 Vienna, Austria, September 1-6, pp. 23-31.

Gross, S., Malinova, M. and Mendling, J. (2019), "Navigating through the maze of business process change methods", Proceedings of the 52nd Hawaii International Conference on System Sciences (HICSS-52), Maui, Hawaii, pp. 6270-6279.

Hammer, M., Champy, J. and Revised (1993), "Reengineering the corporation: a manifesto for business revolution", Harper Business, available at: http://journals.aom.org/doi/10.5465/amr.1994. 9412271824.

Harmon, P. and Garcia, J. (2020), “The state of business process management 2020", BPTrends, available at: http://www.bptrends.com/bpt/wp-content/uploads/2020-BPM-Survey.pdf.

Hartmann, P.M., Zaki, M., Feldmann, N. and Neely, A. (2014), "Big data for big business? A taxonomy of data-driven business models used by start-up firms", available at: https:// cambridgeservicealliance.eng.cam.ac.uk/resources/Downloads/Monthly Papers/2014_March_ DataDrivenBusinessModels.pdf.

Haselbock, S., Weinreich, R., Buchgeher, G. and Kriechbaum, T. (2018), "Microservice design space analysis and decision documentation: a case study on API management", 2018 IEEE 11th Conference on Service-Oriented Computing and Applications (SOCA), IEEE, pp. 1-8.

Huang, S.Y., Lee, C.H., Chiu, A.A. and Yen, D.C. (2015), "How business process reengineering affects information technology investment and employee performance under different performance measurement”, Information Systems Frontiers, Vol. 17 No. 5, pp. 1133-1144.

Jaakonmäki, R., Simons, A., Müller, O. and vom Brocke, J. (2018), "ECM implementations in practice: objectives, processes, and technologies”, Journal of Enterprise Information Management, Vol. 31 No. 5, pp. 704-723.

Jain, R., Aagja, J. and Bagdare, S. (2017), "Customer experience - a review and research agenda", Journal of Service Theory and Practice, Vol. 27 No. 3, pp. 642-662.

Jeston, J. and Nelis, J. (2008), Business Process Management: Practical Guidelines to Successful Implementations, 2nd ed., Elsevier/Butterworth-Heinemann, available at: https://books.google. at/books?id=Msb4W7prLTgC.

Kaplan, R.S. and Norton, D.P. (1993), "Putting the balanced scorecard to work", Harvard Business Review, September-October, pp. 134-149.

Kerpedzhiev, G.D., König, U.M., Röglinger, M. and Rosemann, M. (2020), "An exploration into future business process management capabilities in view of digitalization", Business and Information Systems Engineering. doi: 10.1007/s12599-020-00637-0.

Kettinger, W.J., Teng, J.T.C. and Guha, S. (1997), "Business process change: a study of methodologies, techniques, and tools", MIS Quarterly, Vol. 21 No. 1, pp. 55-80.

Kirchmer, M. (2017), "Business process management: what is it and why do you need it?", in High Performance Through Business Process Management, Springer International Publishing, Cham, pp. 1-28.

Knutson, B.J. and Beck, J.A. (2004), "Identifying the dimensions of the experience construct", Journal of Quality Assurance in Hospitality and Tourism, Vol. 4 Nos 3-4, pp. 23-35.

König, U.M., Linhart, A. and Röglinger, M. (2019), "Why do business processes deviate? Results from a Delphi study", Business Research, Vol. 12 No. 2, pp. 425-453.

Koschmider, A., Zwickau, W.H. and Fellmann, M. (2019), "Business process model anti- Patterns : a bibliography and taxonomy of published work", Proceedings of the 27th European Conference on Information Systems (ECIS), Stockholm and Uppsala.

Kotler, P., Burton, S., Deans, K., Brown, L. and Armstrong, G. (2012), Marketing, 9th ed., Pearson Australia, Frenchs Forest. 
BPMJ 27,8

Koutsopoulos, G. and Bider, I. (2018), Business Process Canvas as a Process Model in a Nutshell, Lecture Notes in Business Information Processing, Springer International Publishing, Cham, Vol. 318, doi: 10.1007/978-3-319-91704-7_4.

Kulshrestha, A. (2017), "DocOnline to expand to 7 cities; ventures into B2C segment", Economic Times, October, available at: https://economictimes.indiatimes.com/industry/healthcare/biotech/ healthcare/doconline-to-expand-to-7-cities-ventures-into-b2c-segment/articleshow/61011503.cms (accessed 4 November 2019).

Kwak, Y.H. and Anbari, F.T. (2006), "Benefits, obstacles, and future of six sigma approach", Technovation, Vol. 26 Nos 5-6, pp. 708-715.

Laguna, M. and Marklund, J. (2013), Business Process Modeling, Simulation and Design, Chapman and Hall/CRC, Boca Raton, FL.

Lapouchnian, A., Yu, E. and Sturm, A. (2015), "Re-designing process architectures towards a framework of design dimensions", 2015 IEEE 9th International Conference on Research Challenges in Information Science (RCIS), Vol. 2015 June, IEEE, pp. 205-210.

Lee, J. (2014), “A grammatical approach to process design and its evaluation based on problem space”, Academy of Information and Management Sciences Journal, Vol. 17 No. 2, pp. 113-135.

Lee, J., Wyner, G. and Pentland, B. (2008), "Process grammar as a tool for business process design", MIS Quarterly, Vol. 32 No. 4, p. 757.

Lillrank, P. (2003), "The quality of standard, routine and nonroutine processes", Organization Studies, Vol. 24 No. 2, pp. 215-233.

Lohmann, P. and zur Muehlen, M. (2015), "Business process management skills and roles: an investigation of the demand and supply side of BPM professionals", in Motahari-Nezhad, H.R., Recker, J. and Weidlich, M. (Eds), Lecture Notes in Computer Science Book Series (LNCS), Springer International Publishing, Cham, Vol. 9253, doi: 10.1007/978-3-319-23063-4.

Maclean, A., Young, R.M., Victoria, M.E. and Moran, T.P. (1991), "Questions, options , and criteria : elements of design space analysis”, Human-Computer Interaction, Vol. 6 Nos 3-4, pp. 201-250.

Maddern, H., Smart, P.A., Maull, R.S. and Childe, S. (2014), "End-to-end process management: implications for theory and practice", Production Planning and Control, Taylor \& Francis, Vol. 25 No. 16, pp. 1303-1321.

Malone, T.W., Crowston, K., Lee, J., Pentland, B., Dellarocas, C., Wyner, G., Quimby, J., Osborn, C.S., Bernstein, A., Herman, G., Klein, M. and O'Donnell, E. (1999), "Tools for inventing organizations: toward a handbook of organizational processes", Management Science, Vol. 45 No. 3, pp. 425-443.

Melao, N. and Pidd, M. (2000), "A conceptual framework for understanding business processes and business process modelling”, Information Systems Journal, Vol. 10 No. 2, pp. 105-129.

Mendling, J., Pentland, B.T. and Recker, J. (2020), "Building a complementary agenda for business process management and digital innovation”, European Journal of Information Systems, Vol. 29 No. 3, pp. 208-219.

Meyer, C. and Schwager, A. (2007), "Understanding customer experience”, Harvard Business Review, Vol. 85 No. 6, p. 137.

Miles, I. (2008), "Patterns of innovation in service industries”, IBM Systems Journal, Vol. 47 No. 1, pp. 115-128.

Mose Biskjaer, M., Dalsgaard, P. and Halskov, K. (2017), "Understanding creativity methods in design", Proceedings of the 2017 Conference on Designing Interactive Systems, ACM, New York, NY, USA, pp. 839-851.

Mudgal, S., Li, H., Rekatsinas, T., Doan, A., Park, Y., Krishnan, G., Deep, R., Arcaute, E. and Raghavendra, V. (2018), "Deep learning for entity matching: a design space exploration", Proceedings of the 2018 International Conference on Management of Data - SIGMOD '18, ACM Press, New York, NY, USA, pp. 19-34. 
Myers, M.D. and Newman, M. (2007), "The qualitative interview in IS research: examining the craft", Information and Organization, Vol. 17 No. 1, pp. 2-26.

Navinchandra, D. (1991), Exploration and Innovation in Design, Springer New York, NY, doi: 10.1007/ 978-1-4612-3114-1.

Nickerson, R.C., Varshney, U. and Muntermann, J. (2013), “A method for taxonomy development and its application in information systems", European Journal of Information Systems, Vol. 22 No. 3, pp. 336-359.

Nivala, A. and Sarjakoski, L.T. (2003), "Need for context-aware topographic maps in mobile devices", ScanGIS'2003 - The 9th Scandinavian Research Conference on Geographical Information Science, Espoo, pp. 15-29.

Nygren, N.V., Jokinen, A. and Nikula, A. (2017), "Unlearning in managing wicked biodiversity problems", Landscape and Urban Planning, Vol. 167, pp. 473-482, doi: 10.1016/j.landurbplan. 2017.06.019.

Nylén, D. and Holmström, J. (2015), "Digital innovation strategy: a framework for diagnosing and improving digital product and service innovation", Business Horizons, Vol. 58 No. 1, pp. 57-67.

Parker, G., Van Alstyne, M. and Choudary, S.P. (2016), Platform Revolution: How Networked Markets Are Transforming the Economy and How to Make Them Work for You, Norton \& Company, New York.

Pourmirza, S., Peters, S., Dijkman, R. and Grefen, P. (2017), "A systematic literature review on the architecture of business process management systems", Information Systems, Elsevier, Vol. 66, pp. 43-58.

Ramias, A. (2018), "Process scope versus project scope", BPTrends Column, available at: https://www. bptrends.com/process-improvement-process-scope-versus-project-scope/.

Reijers, H.A. and Liman Mansar, S. (2005), "Best practices in business process redesign: an overview and qualitative evaluation of successful redesign heuristics", Omega, Vol. 33 No. 4, pp. 283-306.

Reijers, H.A., Limam, S. and Wil, V.D.A. (2003), "Product-based workflow design", Journal of Management Information Systems, Vol. 20 No. 1, pp. 229-262.

Rosemann, M. (2017), "The NESTT: rapid process redesign at queensland university of technology", in vom Brocke, J. and Mendling, J. (Eds), BPMCase Studies, Springer, pp. 169-185.

Rosemann, M. (2019), "Trust-aware process design”, in Hildebrandt, T., van Dongen, B.F., Röglinger, M. and Mendling, J. (Eds), 2019 Proceedings 17th International Conference BPM2019 Vienna, Springer International Publishing, Cham, Austria, September 1-6, Vol. 11675, pp. 305-321.

Rosemann, M. (2020), "Explorative process design patterns", Business Process Management Conference (BPM 2020), Sevilla, Spain, pp. 349-367.

Rosemann, M. and vom Brocke, J. (2015), "The six core elements of business process management", in Handbook on Business Process Management 1, Springer Berlin Heidelberg, Berlin, Heidelberg, pp. 105-122.

Saxena, K.B.C. and Bharadwaj, S.S. (2009), "Managing business processes through outsourcing: a strategic partnering perspective”, Business Process Management Journal, Vol. 15 No. 5, pp. 687-715.

Schultze, U. and Avital, M. (2011), "Designing interviews to generate rich data for information systems research", Information and Organization, Elsevier, Vol. 21 No. 1, pp. 1-16.

Schulz, H.-J., Nocke, T., Heitzler, M. and Schumann, H. (2013), “A design space of visualization tasks", IEEE Transactions on Visualization and Computer Graphics, Vol. 19 No. 12, pp. 2366-2375.

Setiawan, M.A. and Sadiq, S. (2013), "A methodology for improving business process performance through positive deviance", International Journal of Information System Modeling and Design, Vol. 4 No. 2, pp. 1-22.

Sharp, A. and Mcdermoot, P. (2009), Workflow Modeling: Tools for Process Improvement and Applications Development, 2nd ed., Artech House, Norwood, MA, Vol. 104. 
BPMJ 27,8
Sonnenberg, C. and Vom Brocke, J. (2012), "Evaluations in the science of the artificial - reconsidering the build-evaluate pattern in design science research", Lecture Notes in Computer Science, LNCS, Vol. 7286, pp. 381-397.

Spohrer, J., Maglio, P.P., Bailey, J. and Gruhl, D. (2007), "Steps toward a science of service systems", Computer, Vol. 40 No. 1, pp. 71-77.

Straker, K., Wrigley, C. and Rosemann, M. (2015), "Typologies and touchpoints: designing multichannel digital strategies", The Journal of Research in Indian Medicine, Vol. 9 No. 2, pp. 110-128.

van Amstel, F.M.C., Hartmann, T., van der Voort, M.C. and Dewulf, G.P.M.R. (2016), "The social production of design space", Design Studies, Vol. 46, pp. 199-225.

Van den Bergh, J., Thijs, S. and Viaene, S. (2014), “Ambidextrous BPM: making BPM exciting againan interview with prof. Michael Rosemann", in Transforming Through Processes - Leading Voices on BPM, People, and Technology, Springer, Cham, pp. 53-55.

van der Aalst, W.M.P., Bichler, M. and Heinzl, A. (2018), "Robotic process automation", Business and Information Systems Engineering, Springer Fachmedien Wiesbaden, Vol. 60 No. 4, pp. 269-272.

Vanwersch, R.J.B., Vanderfeesten, I., Rietzschel, E. and Reijers, H.A. (2015), "Improving business processes: does anybody have an idea?", International Conference on Business Process Management, Cham, Springer International Publishing, Vol. 9253, pp. 3-18.

Vanwersch, R.J.B., Shahzad, K., Vanderfeesten, I., Vanhaecht, K., Grefen, P., Pintelon, L., Mendling, J., van Merode, G.G. and Reijers, H.A. (2016), "A critical evaluation and framework of business process improvement methods", Business and Information Systems Engineering, Springer Fachmedien Wiesbaden, Vol. 58 No. 1, pp. 43-53.

Veit, D., Clemons, E., Benlian, A., Buxmann, P., Hess, T., Kundisch, D., Leimeister, J.M., Loos, P. and Spann, M. (2014), "Business models - an information systems research agenda", Business and Information Systems Engineering, Vol. 6 No. 1, pp. 45-53.

Venable, J., Pries-Heje, J. and Baskerville, R. (2016), "FEDS: a framework for evaluation in design science research", European Journal of Information Systems, Vol. 25 No. 1, pp. 77-89.

Wagner, K.W. and Patzak, G. (2015), Performance Excellence-Der Praxisleitfaden Zum Effektiven Prozessmanagement, Carl Hanser Verlag, Munich.

Weinmann, M., Schneider, C. and vom Brocke, J. (2016), "Digital nudging”, Business and Information Systems Engineering, Springer Fachmedien Wiesbaden, Vol. 58 No. 6, pp. 433-436.

Wurm, B., Goel, K., Bandara, W. and Rosemann, M. (2019), "Design patterns for business process individualization”, 2019 Proceedings 17th International Conference BPM2019 Vienna, Austria, September 1-6, Springer International Publishing, Vol. 1, pp. 370-385.

Zellner, G. (2011), “A structured evaluation of business process improvement approaches”, Business Process Management Journal, Vol. 17 No. 2, pp. 203-237.

Zhu, X., Recker, J., Zhu, G. and Maria Santoro, F. (2014), "Exploring location-dependency in process modeling", Business Process Management Journal, Vol. 20 No. 6, pp. 794-815.

\section{Corresponding author}

Steven Gross can be contacted at: steven.gross@wu.ac.at 


\section{Appendix 1}

\section{Background information on professional process experts (interviewees)}

To substantiate our results, we included six professional process experts into the third iteration of the deployed taxonomy development method. We thereby included a professional perspective on the process redesign task, after accounting for an academic perspective in the first two iterations. All experts were experienced with process redesign projects in different domains. Three process experts (I1, I2, I3) were process consultants (all operating in central Europe) focusing on medium and large-sized organizations in various industries. One expert (I4) consulted start-ups and entrepreneurs in Austria, thus mainly focused on the design of new BPs. The last two experts were responsible for BPM and related activities within their organizations, which were large-sized organizations, in the telecommunication (I5) and finance (I6) industry in Central Europe. More details on the interviewees can be found in Table A1.

\begin{tabular}{|c|c|c|c|c|c|}
\hline ID & Current position/job title & $\begin{array}{l}\text { Work } \\
\text { experience }\end{array}$ & $\begin{array}{l}\text { Academic } \\
\text { background }\end{array}$ & Industry & Employees \\
\hline I1 & Management consultant & $>18$ years & $\begin{array}{l}\text { Business } \\
\text { administration }\end{array}$ & $\begin{array}{l}\text { Service-business } \\
\text { consulting }\end{array}$ & 1 (2019) \\
\hline $\mathrm{I} 2$ & $\mathrm{CEO} /$ process consultant & $>24$ years & Engineering & $\begin{array}{l}\text { Service - business } \\
\text { consulting }\end{array}$ & 26 (2019) \\
\hline I3 & $\begin{array}{l}\text { Authorized officer/ } \\
\text { process consultant }\end{array}$ & $>15$ years & Economics & $\begin{array}{l}\text { Service - business } \\
\text { consulting }\end{array}$ & 3 (2019) \\
\hline I4 & $\mathrm{CEO} /$ chief disruptor & $>18$ years & $\begin{array}{l}\text { Business } \\
\text { administration }\end{array}$ & $\begin{array}{l}\text { Service - business } \\
\text { consulting }\end{array}$ & $4(2019)$ \\
\hline I5 & $\begin{array}{l}\text { Process and quality } \\
\text { manager }\end{array}$ & $>13$ years & $\begin{array}{l}\text { Business } \\
\text { administration }\end{array}$ & $\begin{array}{l}\text { Service - } \\
\text { communication }\end{array}$ & $\begin{array}{l}18,700 \\
(2018)\end{array}$ \\
\hline I6 & $\begin{array}{l}\text { Settlement and collateral } \\
\text { management }\end{array}$ & $>2$ years & $\begin{array}{l}\text { Information } \\
\text { systems }\end{array}$ & $\begin{array}{l}\text { Service - financial } \\
\text { services }\end{array}$ & $1,100(2019)$ \\
\hline
\end{tabular}

Table A1. Overview of the industry experts

\section{Appendix 2}

\section{Iterations of the taxonomy development}

To provide details on the taxonomy development process, Table A2 lists all iterations and gives details on the applied approach, the number of dimensions and layers, the identification or modification of dimensions and layers and, finally, the fulfillment of the predefined ending conditions. 


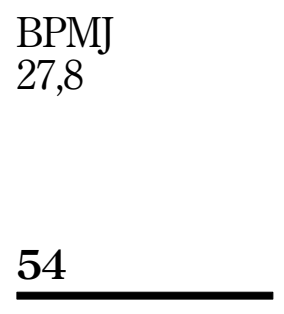

Table A2.

Additional information to the iterations of the applied taxonomy development method
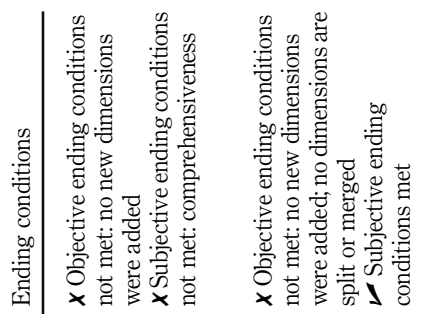

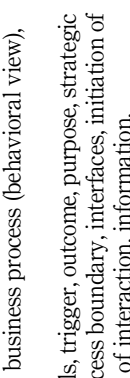

峁

苛. 离

总宓.

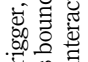

E.

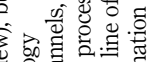

응 矛芯泀

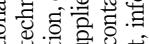

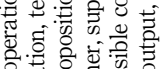

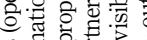

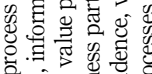

के $\hat{0}$.

焉焉总

官造焉

कि

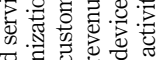

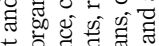

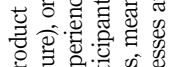

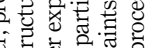

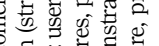

站寻 范

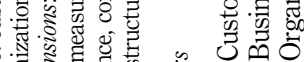

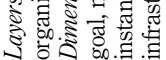

今

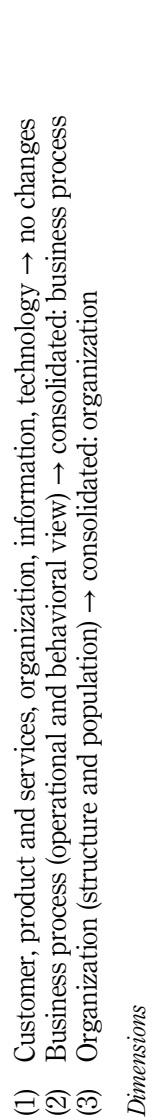

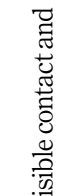

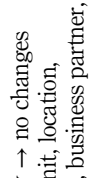

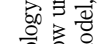

들

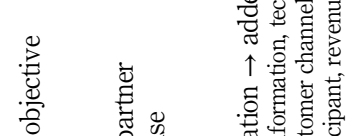

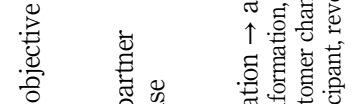

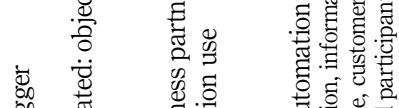

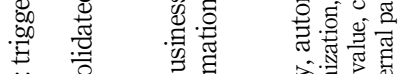

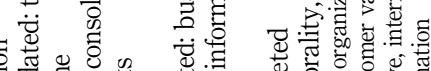

䒿

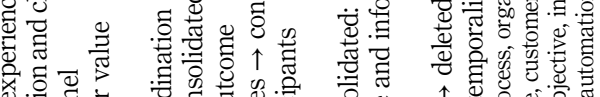

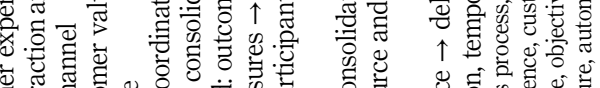

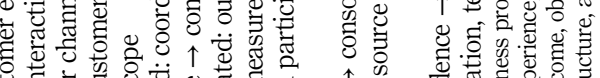

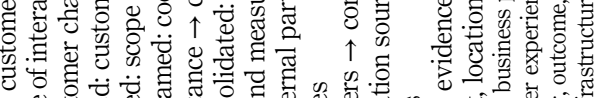

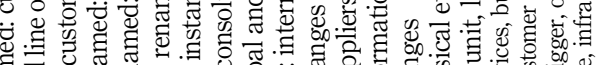

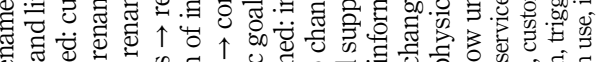

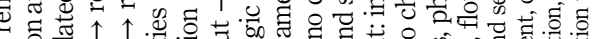

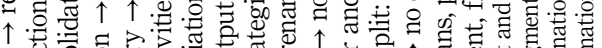

ญ

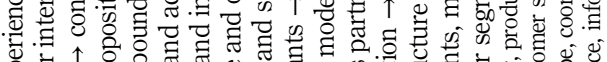

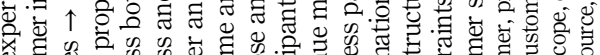

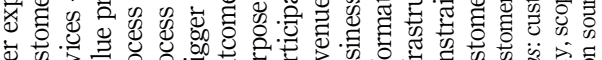

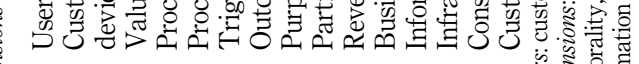

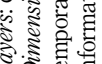

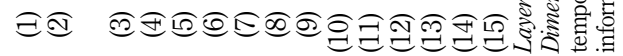

$\infty$

$\stackrel{9}{6}$

Ð

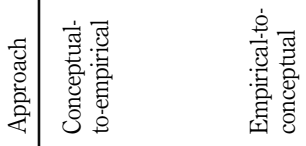

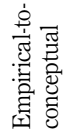

苞

$\infty$ 
Appendix 3

\section{Selected redesign ideas from the real-world applications of the Business Process}

\section{Design Space}

In section 5.2 of the research paper, we describe three real-world applications of the BPD-Space and exemplary redesign ideas for the respective processes. The following tables offer additional redesign ideas that were created in the course of these workshops. Triggering dimension indicates which design dimension sparked the corresponding redesign idea.

\section{Business process design space}

Generated process redesign alternatives

Segment customers based on age: younger customers answer process-related questions through relevant pictures, while older customers answer through text choices

Automatic detection of customer segments based on customer and device-specific information

New users can receive service-related information from friends or family members, e.g. their products and choices (if they consent)

Offering the functionality for customers to share profiles of consultants for the referral to friends and family members

Scheduling and offering online group consultations, e.g. for members of a family

Offering a forum on the platform in which customers can ask (anonymous) questions and consultants can answer

Offering the platform for similar matching problems between customers and experts, e.g. for lawyers

Filtering for currently available consultants for an instant online consultation

In case the family situation changes, initiate the consultation process with contextspecific products/services

Use Apple wallet to share the business card of a consultant with the customer

Expand the scope of the process by integrating other actors into the platform to cover the whole use case of the customer, e.g. lawyers for real estate financing

Advertise the service and/or specific consultants through flyer and posters with QR codes, which directly link to the consultant on the platform

Provide the possibility to indicate if a consultation was useful (in the form of ratings), Customer value such that this information is provided for other customers
Triggering dimension

Customer segment

Customer segment

Customer experience

Customer value

Customer experience

Customer channel

Flow unit

Temporality

Trigger

Business partner

Scope

Trigger

Table A3. Selected process redesign ideas for baningo 
Offer maintenance activities outside of the laboratory operating hours (saves time)

Customer value

Integrate customer training with the maintenance activities (rewards me)

Customer value

Integrate the modification of devices (e.g. an required update or security fix) with

maintenance activities, two previously separated processes

Flow unit

Offer the customer to conduct the maintenance guided by a remote service engineer and supported by video chat and/or augmented reality technology

Offer the maintenance on-demand instead of having fixed intervals, e.g. after a certain throughput has been reached

During the maintenance-related downtime, offer to provide test results through Scope partnering laboratories nearby (if possible)

In case a customer cannot schedule an appointment at a date/time of convenience, offer the option to schedule a more remote service engineer at additional costs

Location

Gather information at the customers site regarding competitor devices used for future proposal preparation

Gather and aggregate attrition data during the device maintenance, which can be used by the R\&D department for adaptations of existing or design of future devices

Temporality

Outcome

Information source

Information use

Build and operate a customer facing portal, which can be used to schedule maintenance activities

Table A4.

Selected process redesign ideas for Labnetic
Integrate a scheduling system to best utilize service engineers, e.g. to schedule maintenance activities that are geographically close on the same day/week
Infrastructure

Automation
Generated process redesign alternatives

Using social media to interact with the customer, e.g. in case of questions or status updates

Send SMS to update customer about the processing status

Provide option to order an all-inclusive package, including the provision of a new grid connection as well as all home connections

Provide option to book accompanying workshops, e.g. regarding electricity safetyrelated topics

Send the customer monthly updates about the energy consumption of the household, e.g. to indicate significant changes in the consumption behavior

Provide a platform on which customers can exchange construction and householdrelated information

Table A5.

Selected process redesign ideas for ELECTRO
Enable more employees at different positions to provide customer services or to accept an order, e.g. a client advisor at a brand office or an administrative assistant at the headquarters

Use robotic process automation to support order entries or contract building
Triggering dimension

Customer channel

Customer channel

Scope

Scope

Information use

Customer value

Internal participants

Automation 